\title{
Brain Indices of Music Processing: "Nonmusicians" are Musical
}

\author{
Stefan Koelsch, Tomas Gunter, and Angela D. Friederici
}

Max Planck Institute of Cognitive Neuroscience

Erich Schröger

University of Leipzig

\begin{abstract}
Only little systematic research has examined event-related brain potentials (ERPs) elicited by the cognitive processing of music. The present study investigated how music processing is influenced by a preceding musical context, affected by the task relevance of unexpected chords, and influenced by the degree and the probability of violation. Four experiments were conducted in which "nonmusicians" listened to chord sequences, which infrequently contained a chord violating the sound expectancy of listeners. Integration of in-key chords into the musical context was reflected as a late negative-frontal deflection in the ERPs. This negative deflection declined towards the end of a chord sequence, reflecting normal buildup of musical context. Brain waves elicited by chords with unexpected notes revealed two ERP effects: an early right-
\end{abstract}

\section{INTRODUCTION}

The major aim of the present study was the investigation of neural processes reflecting (a) the buildup of a musical context, (b) the integration of musical information into a musical context, and (c) the violation of musical expectancies induced by a musical context. Investigating these issues aimed on exploring similarities and differences between music and language processing, especially in respect of the syntactic and semantic nature of music.

When a person sings, plays an instrument, or speaks a sentence, a succession of acoustic events is normally supposed to constitute a context, which can be understood by another person. Hence, cognitive processes of both context buildup and the integration of appropriate new information into a context are substantial for understanding music, as well as language. In western tonal music, a musical context always refers to a tonal center (or tonal key), which is ideally represented by the tonic chord (in $C$ major: $C-e-g$ ). Notably, the tonal center of a musical context is not explicitly inherent in each of its notes or chords, since every note or chord always belongs to several different keys. To understand a hemispheric preponderant-anterior negativity, which was taken to reflect the violation of sound expectancy; and a late bilateral-frontal negativity. The late negativity was larger compared to in-key chords and taken to reflect the higher degree of integration needed for unexpected chords. The early right-anterior negativity (ERAN) was unaffected by the task relevance of unexpected chords. The amplitudes of both early and late negativities were found to be sensitive to the degree of musical expectancy induced by the preceding harmonic context, and to the probability for deviant acoustic events. The employed experimental design opens a new field for the investigation of music processing. Results strengthen the hypothesis of an implicit musical ability of the human brain. musical context, listeners have to extract a tonal center by perceiving musical relations between several notes (see Krumhansl \& Kessler, 1982). Within a musical context, some musical events are more expected by listeners than others. The aesthetic violation of sound expectancies, musical surprises, ambiguation and disambiguation of musical events are perceived as appealing by most listeners. Composers expanded the repertoire of dissonances and ambiguities throughout the history of music, otherwise music would have become boring.

\section{Music Perception as Revealed by Subjective Measures}

Investigating perceived relations between tones, Krumhansl (1979) found that in a tonal environment tones of the tonic chord (in $C$ major: $c-e-g$ ) are perceived as most closely related to each other. The remaining diatonic scale tones (in $C$ major: $d, f, a, b$ ) are less closely related, and the nondiatonic tones ( $c \#, d \#, f \#$, $g \#$, and $a \#)$ are least closely related. Bharucha and Krumhansl (1983) proposed as a basic structural principle governing the representation of harmony, a "hier- 
archy of stability" that applies to these twelve tones of the chromatic scale within an octave range. The concept of stability refers to the fact that certain tones are perceived as more final and serve as better completions of melodic phrases than do other tones, which demand "resolution" to more stable tones in the system.

Changes in the perceived stability of tones are closely linked with the perception of the tonal stability of chords because chords are the simultaneous sounding of tones (Krumhansl \& Kessler, 1982). The tonic chord is the most stable chord, followed by the chords built on the fifth, the fourth, sixth, and second scale tones (Bharucha \& Krumhansl, 1983). Bharucha and Krumhansl (1983) also found that these chords are, similarly to the twelve scale tones, represented in a hierarchy of stability that is dependent upon the prevailing context. Tonic, subdominant, and dominant are the chords of the harmonic core, and perceived as more closely related to each other compared to other chords from the key but not in the core. Chords outside the prevailing key produce very unstable effects, demanding resolution to the more stable harmonies of the system (Bharucha \& Krumhansl, 1983; see Krumhansl, 1979 for review). The psychological establishment of "focal points" around which stable tones or chords locate themselves activates a tonal schema, which specifies a hierarchy of stability (a tonal hierarchy) of all possible tones and chords. The establishment of a tonal hierarchy is the basis for the buildup of a musical context. After such a hierarchy has been established, usually within the first few chords of a musical sequence, unstable tones or chords seem to interfere or clash with the stable tonal fabric unless they are resolved (Bharucha, 1984).

The hierarchy of stability of musical events within a musical context can be well described in terms of psychological distances (Bigand, Madurell, Tillmann, \& Pineau, 1999; Bharucha \& Krumhansl, 1983; Krumhansl, Bharucha, \& Castellano, 1982b; Krumhansl, Bharucha, \& Kessler, 1982a; Krumhansl \& Kessler, 1982). Interestingly, these distances reflect music-theoretical principles of the major/minor tonal system (most common in western tonal music) fairly well. The perception of musical relations within a hierarchy of tonal stability enables a listener to perceive and appreciate tension and release. For example, moving away from a tonal center to unstable chords (or keys) is perceived as tensioning, returning to the stable tonal center as releasing. The course of tension and release also forms the musical context.

Dissonance can produce or enhance tension. Since the perception of tension is only possible with the experience (i.e., knowledge) of release, musical expectancy in form of anticipated release is vital to our musical experience. A chord generates expectancies for related chords to follow, a musical context primes the processing of chords related to the context (relative to chords unrelated to the context), and a musical context induces expectations by activating tonal representations (Bharucha \& Stoeckig, 1986; Bharucha \& Stoeckig, 1987; see also Bigand et al., 1999). The interplay between expectancies, as they unfold over time, and the varying degrees to which they are fulfilled or violated are broadly considered as fundamental for the appreciation of music (e.g., Hantz, Kreilick, Kananen, \& Swartz, 1997; Berent \& Perfetti, 1993; Bharucha, 1984; Bharucha \& Stoeckig, 1986; Bharucha \& Stoeckig, 1987; Jones, 1981a; Jones, 1981b; Schönberg, 1957; Meyer, 1956). In respect to the present study, it is important to note that the expectancy of an acoustic event is not just determined by tonal, or harmonic, features, but also by the timbre of a sound (see Schröger, 1998; Platel et al., 1997; Tervaniemi, Winkler, \& Näätänen, 1997).

The mental representation of tonality is established by the listeners within only very few tones (or chords). Though musical information is always ambiguous, listeners rather commit themselves to this representation than to the ambiguous nature of musical information (Berent \& Perfetti, 1993; Krumhansl \& Kessler, 1982). These early decisions will sometimes turn out to be erroneous in the subsequent musical context. The listener will then experience a parsing failure, and a repair, or reinterpretation, might be made. According to Berent and Perfetti (1993), the events that brought about the parsing failure and required the reinterpretation may be further perceived as unexpected.

\section{Electrophysiology and Music Versus Language Processing}

Only recently, event-related brain potential (ERP) researchers discovered the investigation of cognitive processes underlying the perception of music. Up to now, merely a small number of ERP studies of music processing have been conducted (cf. Besson \& Friederici, 1998). Most ERP studies exploring music processing have shown positive deflections to be associated with music incongruities for both melodic (e.g., Besson and Faïta, 1995; Besson \& Friederici, 1998) and polyphonic stimuli (e.g., Janata, 1995). Making a direct comparison between music and language, Patel, Gibson, Ratner, Besson, and Holcomb (1998) found that both linguistic and musical structural incongruities elicited positivities with a latency of about $600 \mathrm{msec}$ (posteriorly maximal). This so-called P600, until then only associated to syntactic language processing (Hagoort, Brown, \& Groothusen, 1993), was interestingly, statistically indistinguishable for both language and music processing. Thus, Patel et al. (1998) suggested that the P600 probably reflects a more general knowledge-based structural integration during the perception of rule-governed sequences. Moreover, language-related syntactic processing also elicits left-anterior negativities, either in an early or a later time frame (for discussion, see Gunter \& Friederici, 1999; Friederici, 1995). A similar negative 
component elicited by the processing of music but distributed over the right hemisphere has been described by Patel et al. (1998) as the right anteriotemporal negativity (RATN). This component was taken to reflect the application of music-specific rules or music-specific working memory resources.

Besides syntactic processing, semantic processing also plays a major role in language understanding. As has been known for the last decade, semantic processing is reflected in a negative component being maximal around $400 \mathrm{msec}$, called the N400 (for review, see Kutas \& Dale, 1997). The N400 is typically taken to reflect semantic integration processing, the more difficult the integration, the larger this component. Interestingly, a component similar to the N400 has, so far, not been reported for the processing of music, although the integration of musical events into a musical context is vital for the understanding of music. However, the investigation of this issue has been difficult, probably due to the fact that semantics in language is much more explicit compared to music.

The present study employed an experimental paradigm, in which the basic stimulus material consisted of chord sequences (in musical terms "cadences") of five in-key chords from the same key (Figure 1a). Each of these in-key chord sequences began and ended with a tonic chord, and built up a musical context towards the end of each cadence. The chord sequences were pre-

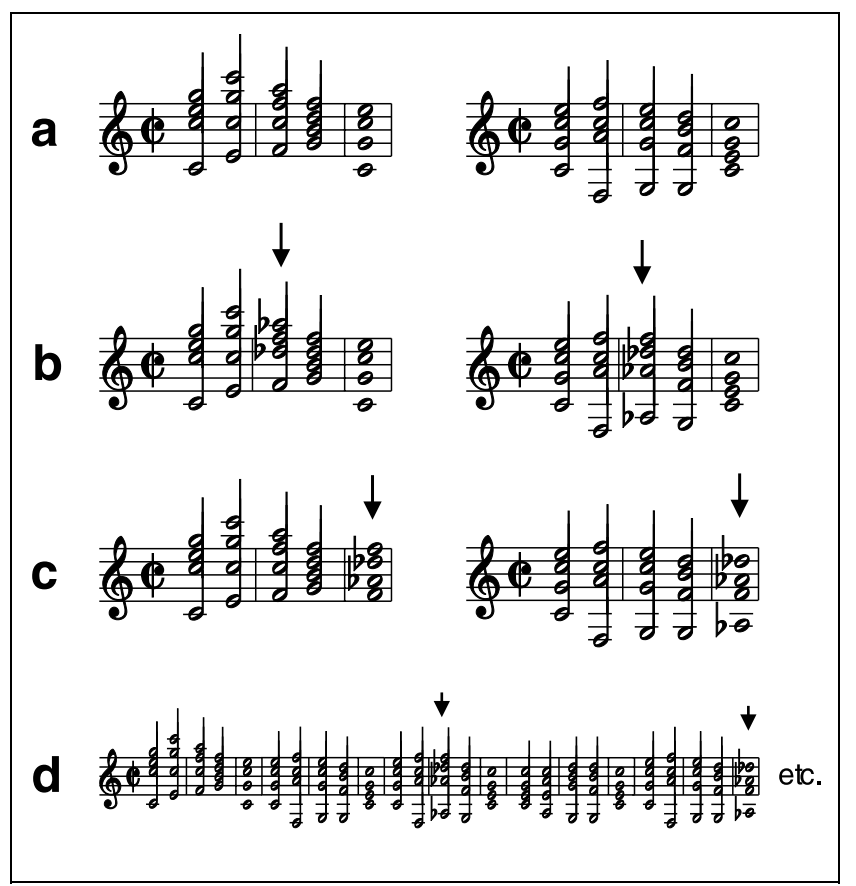

Figure 1. Examples of chord sequences. (a) Cadences exclusively consisting of in-key chords; (b) cadences containing a Neapolitan sixth chord at the third position, and (c) cadences containing a Neapolitan at the fifth position, Neapolitan chords are indicated by arrows. (d) Example of directly succeeding chord sequences as presented in the experiment. sented one after the other, in order to give the impression of a musical piece, rather than of a presentation of single experimental stimuli (Figure 1d). Texture of chords followed the classical theory of harmony. It was expected that during such a chord sequence, a tonal schema is activated in listeners, entailing the representation of a tonal key that specifies a hierarchy of harmonic stability (Bharucha, 1984).

To investigate neural processes reflecting both the violation of musical expectancy and a subsequent harmonic integration, chords with out-of-key notes were presented infrequently among in-key chords. As described before, chords containing out-of-key (i.e., "nondiatonic") notes are perceived as more distant from the tonal center (and, therefore, as more unstable) compared to chords consisting of in-key notes. Chords with out-of-key notes interfere with an established stable tonal fabric. They violate the expectancy for tonally related chords to follow which may be experienced as a parsing failure requiring reinterpretation.

Four experiments were conducted: Experiment 1 was performed to investigate musical-context buildup and the processing of musical "violations." Experiment 2 was conducted to investigate an influence of the degree of a violation on music processing. With Experiment 3, we studied the effects of the task relevance of unexpected chords; and with Experiment 4, we studied the effects of probability on the processing of music.

To ensure that results would enable broad generalization, participants of all experiments were "nonmusicians." That is, no participant had ever had musical lessons, or learned playing an instrument or singing (besides normal school education).

\section{EXPERIMENT 1: MUSICAL CONTEXT BUILDUP AND PROCESSING MUSICAL "VIOLATIONS"}

Participants were presented with directly succeeding chord sequences, each consisting of five chords (Figure 1d). In $25 \%$ of all sequences, the chord at the third position and in $25 \%$ the chord at the fifth position, was a "Neapolitan sixth chord" (Figure 1b-c). A Neapolitan chord (in $C$ major: $a$ flat $-f-d$ flat) is a variation of the subdominant (a minor subdominant with a minor sixth instead of a fifth), and contains two out-of-key notes (in $C$ major: a flat and $d$ flat $).{ }^{1}$ Though chords at the fifth position of a sequence were twice as long in duration than chords at the first to fourth position, all chords in the experiment were presented with identical decay (so that Neapolitan chords at the third vs. fifth position were on average physically identical within the first $600 \mathrm{msec}$ ).

Chords were mainly played on a piano, but in $10 \%$ of the chord sequences, an in-key chord at the second, third, fourth or fifth position was played on another (i.e., a "deviant") instrument (e.g., marimba, organ, guitar). Participants were instructed to count these chords. This counting task was devised in order to avoid that the 
participants had to detect the Neapolitan chords (since a conscious detection would have caused potentials that might have overlapped with components reflecting a musical processing). Subjects were not informed about the presence of Neapolitan chords or their nature. Participants' attentional focus was, thus, not directed on the Neapolitan chords.

\section{Results}

\section{Musical Context Buildup}

In-key chords. ERP waveforms of the last three in-key chords are shown in Figure 2a. At frontal sites, a negative ERP deflection was present around $550 \mathrm{msec}$ after the onset of a chord. The amplitude of this negative deflection depended on the position in the cadence: It declined towards the end of the cadence. An analysis of variance employing position in the cadence (third vs. fourth vs. fifth chord) as within-subjects factor in the time window from 550 to 610 msec revealed an effect of position $(F(2,32)=4.42, p<.05)$. At the beginning of a cadence, the amplitude of this negative deflection also tended to decline with progressing in-key chords (Figure $2 b)$.

In order to compare this effect of position in a cadence between two chords with identical harmonic function, ERPs of the in-key chords at the first and fifth positions (both tonic chords) are shown in Figure 2c. The negative ERP deflection around 550 msec differed distinctly in amplitude between the tonic chord presented at the beginning compared to the tonic chord presented at the end of a cadence. The frontal predominance of this negative effect is illustrated by a potential map of the difference wave of the two ERPs (fifth subtracted from first chord), interpolated over the time interval from 550 to $610 \mathrm{msec}$ (Figure 2d).

\section{Musical violations}

Chords at the fifth position. Brain responses of the chords at the fifth position of the chord sequences are shown in Figure 3a (see Figure 11a for potential maps). Compared to in-key chords, Neapolitan chords elicited from around $150 \mathrm{msec}$ poststimulus on a negative component in the ERP, which was right-anteriorly predominant. ANOVAs with factors chord type and lateralization (left frontal vs. right frontal, see Methods) revealed an effect of chord type $(F(1,16)=55.53, p<$ $.0001)$, and an interaction between the two factors $(F(1,16)=7.79, p<.05)$.

Neapolitan chords at the fifth position also elicited a P3a (peaking around $350 \mathrm{msec}$ ), followed by a late negative component with an onset around $380 \mathrm{msec}$ and peaking around $550 \mathrm{msec}$. This late negative component was distributed bilaterally, and maximal at frontal sites. Two-factor ANOVAs (chord type $\times$ lateralization)

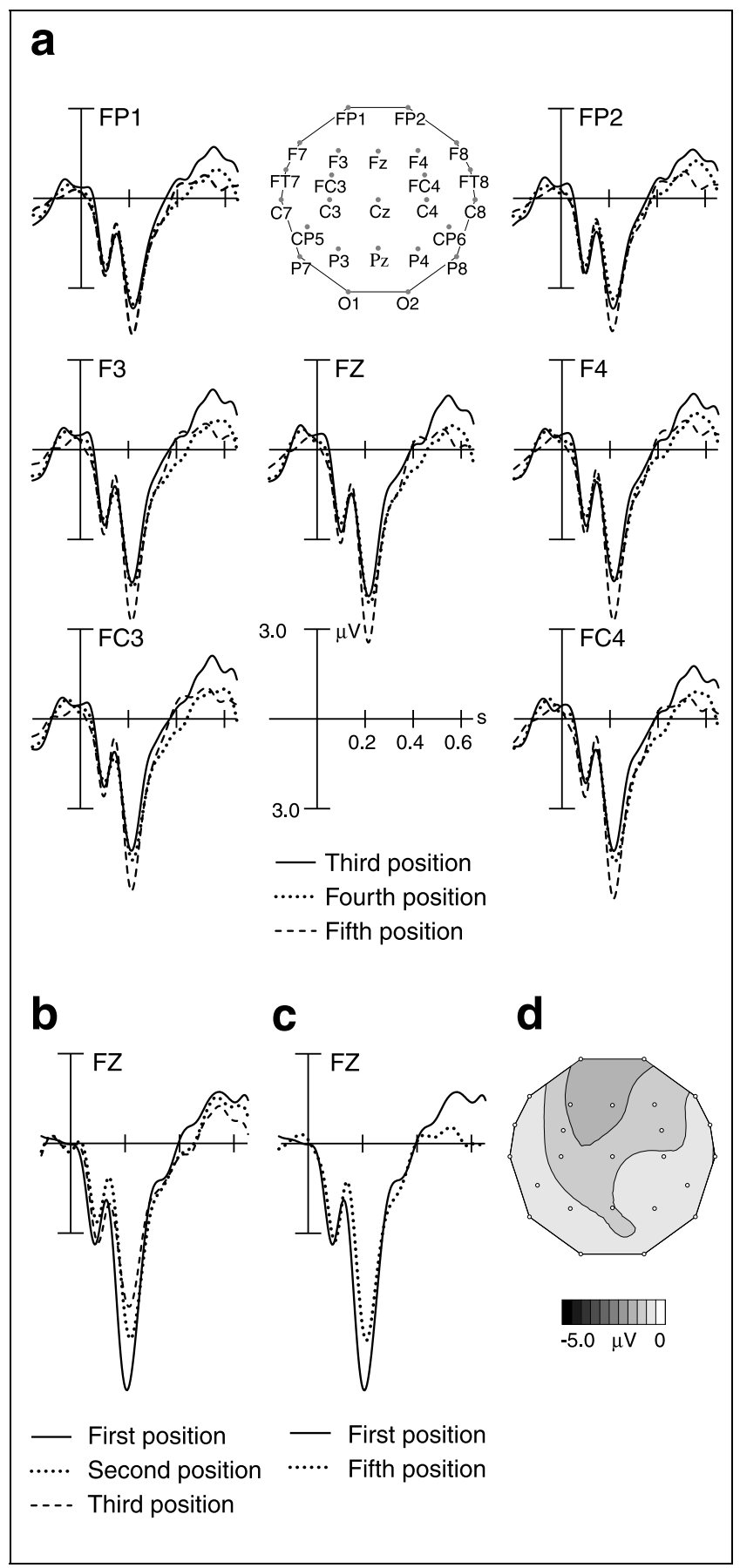

Figure 2. Experiment 1: effects of musical context buildup, Grandaverage ERPs of the in-key chords. (a) Chords at the third, fourth, and fifth positions of the cadence from frontopolar (FP1, FP2), frontal (F3, Fz, F4), and frontocentral (FC3, FC4) electrodes of the 10-20 system. The negative wave deflection (peaking around $550 \mathrm{msec}$ ) is taken to reflect harmonic integration, the decline of this deflection towards the end of the cadence is taken to reflect the buildup of the musical context. (b) Chords at the first, second, and third positions. (c) Chords at the first and fifth positions. (d) Potential map of the difference of the ERPs elicited by in-key chords at the first versus fifth position (fifth subtracted from first chord), interpolated over the time-interval from 550 to $610 \mathrm{msec}$. 




Figure 3. Experiment 1: effects of processing musical violations. (a) Grand-average ERPs of Neapolitans and in-key chords at the fifth position. Neapolitan chords elicited an early right-anterior negativity (ERAN), and a late bilateral negativity (N5). It is suggested that the ERAN reflects the violation of sound-expectancy, and the N5 integration processes. (b) Grand-average ERPs of chords at the third (0-600 ms) and the fourth positions (600-1200 msec). Chords at the third position were Neapolitan and in-key chords. Neapolitan chords elicited a slight ERAN, and a small N5. Effects were smaller when elicited by Neapolitans at the third position compared to Neapolitans at the fifth position, indicating a context-dependent processing of Neapolitan chords.

for the 550-610 msec interval yielded an effect of chord type $(F(1,16)=18.01, p<.001$, no interaction between the two factors).

Chords at the third position. ERPs of chords at the third position of the cadence are shown in Figure $3 \mathrm{~b}$ (see also Figure 11a). The waveforms of in-key chords compared to Neapolitan chords differed much less than those of the chords at the fifth position. Whereas Neapolitan chords at the fifth position elicited a distinct right-anterior negativity with an onset of around 150 msec, this component was only weak, with a later onset, and less distinctly lateralized present in the ERP of the
Neapolitan chords at the third position. Similarly, a P3a and a late-bilateral negativity was merely slightly visible. In sum, the effects elicited by the Neapolitan chords at the third position were very similar, but smaller (and slightly later) than those elicited by the Neapolitan chords at the fifth position. ANOVAs conducted for a 190-250 msec time interval employing factors chord type and lateralization revealed a marginal effect of chord type $(F(1,16)=4.03, p<.07)$, but no interaction between the two factors (however, the lateralization is still visible in the ERPs, and will become significant when analyzed together with data of Experiment 3, see also General Discussion). Analogous ANOVAs for the late interval (550-610 msec) also revealed merely a marginally significant effect of chord type $(F(1,16)=4.06, p<$ .07 , no interaction between the two factors).

Neapolitan chords at the third position also elicited a posteriorly predominant positivity around 400-800 msec. An ANOVA with factor chord type (in-key versus Neapolitan chords) for posterior electrodes (P7, P3, Pz, $\mathrm{P} 4, \mathrm{P} 8)$ revealed an effect of chord type $(F(1,16)=9.34$, $p<.01)$.

To test the differences in amplitude of the early and late negativities elicited by Neapolitan chords presented at the third compared to Neapolitans presented at the fifth position, two-factor ANOVAs were conducted with factors chord type (in-key vs. Neapolitan chords) and position of chords in the cadence (third vs. fifth). ANOVAs for the 150-250 msec time interval (covering the relevant time window for the violation at the fifth and third positions) revealed an effect of chord type $(F(1,16)=62.65, p<.0001)$ and an interaction between the two factors $(F(1,16)=17.61, p<.001)$. The analogous ANOVAs for the 550-610 msec interval also revealed an effect of chord type $(F(1,16)=16.74, p<$ $.001)$, and an interaction between the factors $(F(1,16)=$ $21.30, p<.001)$. ANOVAs, thus, indicate that both early and late negativities elicited by Neapolitan chords differed in amplitude between third versus fifth position.

The effects of chords which were infrequently played by another instrument compared to chords played on a piano will be evaluated together with data of Experiment 2. Only 15 cadences with a chord played by a deviant instrument were employed, since this condition initially only served to direct the participants' attention away from the harmonic dimension of the stimulation.

\section{Discussion}

\section{Building Up a Musical Context}

In-key chords in a cadence elicited an ERP effect, which varied systematically as a function of the position in the cadence: ERP waves of in-key chords showed a negativefrontal deflection with a latency of about $550 \mathrm{msec}$, which decreased in amplitude towards the end of the cadence (Figure $2 \mathrm{a}-\mathrm{b}$ ). It is suggested that this negativ- 
ity reflects a musical integration of in-key chords into the preceding harmonic context, and that the amplitude reduction of this negativity reflects the buildup of musical context.

Cadences were composed in such a way that from a music-theoretical point of view a musical context was built up, and a key was specified with progressing in-key chords towards the end of each cadence. Whereas the first two chords of a chord sequence did not clearly establish a key (e.g., a $\mathrm{C}$ major chord followed by an $\mathrm{A}$ minor chord may establish $\mathrm{C}$ major, $\mathrm{G}$ major, $\mathrm{F}$ major, A minor, E minor, and D minor), a key was unequivocally established after four chords.

It has already been shown that this music theoretically derived establishment of a tonal key is cognitively represented in listeners (Bharucha \& Krumhansl, 1983; Krumhansl \& Kessler, 1982). While listening to a chord sequence, listeners specify a hierarchy of harmonic stability and perceive the increasing stability of the musical context. Therefore, each chord has to be integrated into the musical context (suggested to be reflected in the present data as the negative-frontal deflection peaking around $550 \mathrm{msec}$ ). Since all progressing in-key chords of a cadence built up a musical context (and were compatible with one single key), the developing sense of key (and, thereby, the specificity of the hierarchy of harmonic stability) was represented in the brains of listeners, and supported with progressing chords of a chord sequence. Thus, the further the position of an in-key chord in the cadence, the easier it could be integrated into the musical context established by the preceding chords (suggested to be reflected in the amplitude decline of the negative-frontal deflection).

It is interesting to note that such a similar amplitude reduction is also present in ERPs elicited by words across the course of a sentence. Commonly, this "N400" (or "N4") reduction is interpreted as the reflection of semantic context buildup during sentence comprehension (Van Petten \& Kutas, 1990). As a working term, we label the negative-frontal deflection elicited by music (being maximal around 500-550 msec) the "N5."

Importantly, the amplitude of the N5 was dependent rather on the position in a cadence than on the amount of different chord functions presented at each position of the cadences: The N5 is larger at the fourth compared to the fifth position (though only one chord function occurred at the fourth position), and the N5 is larger at the first compared to the fourth position (though at both positions only one chord function occurred). Thus, the position effect of the N5 cannot be due to regularities of the experiment itself.

\section{Processing Musical Violations}

Neapolitan chords at the fifth position. Neapolitan chords at the fifth position of the chord sequences elicited a distinct early negative deflection in the ERP that had an onset of around $150 \mathrm{msec}$ (Figures 3a, 11a). This deflection was fronto-temporally predominant and right larger in amplitude than left. As a working label for this effect, this deflection will be termed here the early right-anterior negativity, or ERAN. The ERAN is suggested to reflect the brain's response to the violation of sound expectancy: With respect to the preceding harmonic context, Neapolitan chords contained two out-of-key notes (in $C$ major: A flat and $D$ flat) and, therefore, modulated the sound of chords in a way that was not expected in the established tonal environment. Moreover, the remaining in-key note of the Neapolitan chords (in $C$ major: $f$ ) was also unexpected, since it did not match with the expected tonic (in $C$-major: $c-e-g$ ). Thus, Neapolitan chords at the fifth position contained three unexpected notes.

It was described in the Introduction that the perceived distances between chords (and keys, respectively) within a tonal context follow the principles of music theory. A musical context induces expectations for related chords to follow by activating representations of distance and relatedness. Moreover, the more distant a chord in respect of a preceding harmonic context, the less expected it is. Such expectancies were clearly violated in this experiment by the Neapolitan chords, since a Neapolitan can (at least from a musictheoretical perspective) also be interpreted as the sixth chord of the flattened second degree, i.e., as a chord that is at least five fifths (in the sense of the circle of fifths) distant.

The principles, or "rules," of music theory that are reflected in the harmonic expectancies of listeners may be termed "syntax." Interestingly, syntactic violations in auditory language experiments have been found to be reflected in the ERP as an early leftanterior negativity, or "ELAN" (cf. Friederici, Pfeifer \& Hahne, 1993; Friederici, 1995). An ERP effect similar to the ERAN has recently been reported in a music experiment performed by Patel et al. (1998), in which unexpected chords elicited a RATN, taken to reflect the application of music-specific syntactic rules. Thus, the electrical reflections of the cognitive processing of syntactic aspects of music seem to be more right distributed, while analogous reflections of the processing of syntactic aspects of language seems to be more lateralized to the left. The term ERAN refers to both the ELAN and the RATN. Whereas the ERAN differs from the RATN in respect of time course and distribution (the ERAN is also clearly visible over the left hemisphere), it differs from the ELAN only in respect of its distribution (the ERAN looks like a mirrored ELAN).

Neapolitan chords at the fifth position also evoked a distinct late-bilateral negativity that was frontally predominant (Figure 3a-b). This component peaked 
around 500-550 msec and is surprisingly similarly distributed over the scalp compared to the effect of musical-context buildup (compare Figure $3 \mathrm{~b}$ and Figure $2 \mathrm{~d}$ ). Because the musical-context buildup was reflected in an amplitude reduction of the N5, the N5 was taken to reflect musical integration processes. Compared to the tonic at the fifth position, Neapolitan chords were harder to integrate into the preceding harmonic context. Neapolitans contained notes that were not compatible with the established tonal schema, and a strong expectancy for the tonic chord (and not for a Neapolitan) was induced by the preceding dominant seventh chord. Thus, it is suggested that the larger late-bilateral negativity elicited by Neapolitans compared to in-key chords reflects the higher degree of integration needed for Neapolitan chords. Interestingly, analogous processes are known from language perception, where semantically incorrect words in a sentence elicit an "N400" (or "N4"), which is taken to reflect semantic integration (see, e.g., Brown \& Hagoort 1993; Holcomb \& Neville 1991).

We assume processes of the modulation of the hierarchy of the established tonal stability as connected to the integration of Neapolitan chords, since a Neapolitan chord might, for example, introduce a shift to a new key. This process has already been evidenced in behavioral studies (Krumhansl \& Kessler, 1982, p. 360); thus, this process may also be reflected in the ERPs.

A decrease of stability is connected to an increase in demand of resolution (Bharucha \& Krumhansl, 1983; Bharucha, 1984), i.e., increase of expectation of further musical events. Consequently, following Bharucha (1984), a "need of resolution" is presumably also entailed in the processes of integration, since Neapolitan chords contain out-of-key notes that clash with the stable tonal fabric and can be resolved (e.g., by leading via a subsequent dominant seventh chord into the tonic). Notably, Neapolitan chords are ambiguous, since they may be interpreted as a subdominant variation, but they may as well be interpreted as a chord introducing a shift to a new key (e.g., by the interpretation as the subdominant of A flat major).

The late-bilateral negativity elicited by Neapolitan chords is also termed here the N5. An N5 was, thus, not only elicited by in-key chords, but also by Neapolitans (with an enhanced amplitude compared to in-key chords). Notably, the processing of both, a progressing in-key chord and a Neapolitan chord involves integration (entailing either specification or modulation of the hierarchy of stability), and is reflected electrically with a similar time course and scalp distribution.

Effects of position. Neapolitan chords at the third position of a chord sequence also elicited (compared to in-key chords at the same position) an ERAN and an N5 (Figures 3b, 11a). These two effects were distinctly smaller for the Neapolitan chords at the third position than for the Neapolitans at the fifth position. That is, the same Neapolitan chords elicited ERP effects that differed significantly in amplitude due to the position in the chord sequence. It is hypothesized that Neapolitan chords violated the sound expectancy of listeners to a higher degree when presented at the fifth position (compared to the third position), and that Neapolitans required a larger amount of integration when presented at the fifth position. The effect of position on both ERAN and N5 would then indicate that the ERAN is sensitive to the degree of sound expectancy violation, and that the $\mathrm{N} 5$ is sensitive to the degree of required musical integration.

Three arguments strengthening these hypotheses can be derived from both music theory and music psychology: (1) A tonal schema was established by progressing in-key chords, each chord strengthening the hierarchy of harmonic stability and specifying the sound expectancy for related subsequent chords (reflected in the amplitude decline of the N5 elicited by in-key chords). Thus, the sound expectancy was violated to a higher degree by a Neapolitan chord at the end of a chord sequence (resulting in a larger ERAN) compared to a Neapolitan presented in the middle of a sequence. Correspondingly, Neapolitan chords required a larger amount of integration with progressing buildup of the harmonic hierarchy, resulting in an enlargement of the N5. (2) As stated before, Neapolitans at the fifth position contained three unexpected notes. In contrast, Neapolitans at the third position contained only two unexpected notes: the out-of-key notes $a$ flat and $d$ flat. The remaining in-key note $f$ is also the root of the subdominant, a chord that was from a music-theoretical perspective to be expected at the third position. Thus, the total amount of unexpected notes (and of notes that had to be integrated) was higher at the fifth compared to the third position. Correspondingly, Neapolitans at the third position function as a subdominant variation and, thereby, as a predominant chord. Thus, they were less unexpected and could be integrated more easily into the tonal context compared to Neapolitans at the fifth position. (3) Chords at the fifth position were preceded by a dominant seventh chord that induces strong expectations for the tonic chord. No such specific expectation was induced for chords at the third position.

Results demonstrate that the musical context determined the processing of both in-key and Neapolitan chords. The amplitude difference of effects elicited in the brains of listeners can be derived from the principles of music theory. Taking into account that participants were "nonmusicians," we take this finding as evidence for an implicit musical ability of the human brain. That is, whether due to long-term exposure or due to an inherent representation of the major/minor tonal system in the human brain, the brain responses of the participants of the present study can be considered as musical.

Late positivity. Neapolitan chords at the third position also elicited a late positivity between 400 and 800 
msec. Neapolitans at the fifth position did not reveal such positivity (possibly due to a compensation of the positive parietal potentials by the negative potentials of the N5 in the same latency window). Late positivities have already been found to correspond with the processing of harmonic incongruities in music (e.g., Patel et al., 1998; Besson \& Faita, 1995). However, the functional significance of this component will not be further examined in the present study, especially because it cannot be excluded that this positivity overlaps in the following experiments with a P3.

P3 effects. Neapolitan chords at both the third and fifth positions also elicited a frontally predominant positivity (maximal around $280 \mathrm{msec}$ ), which is taken here as a P3a. This component is usually elicited by "novel" sounds in classic oddball paradigms. The presence of such a P3a supports the hypothesis that the Neapolitan chords were perceived by the listeners as unexpected (or "novel"). The $\mathrm{P} 3 \mathrm{a}$ is commonly representing attentional processes (e.g., Näätänen, 1992; Ritter \& Ruchkin, 1992); thus, the ERAN might correlate with subsequent allocation of attention, resulting in the detection of a violation.

\section{EXPERIMENT 2: EFFECTS OF THE DEGREE OF VIOLATION}

The second experiment was conducted in order to test whether the ERAN is sensitive to the degree of sound expectancy violation, and the $\mathrm{N} 5$ is sensitive to the degree of required musical integration. Therefore, stimulation of Experiment 2 was identical to Experiment 1, except that Neapolitan chords were replaced by dissonant tone clusters (Figure 4). These clusters consisted of the same amount of unexpected notes as the Neapolitan chords at corresponding positions (see Methods). Contrary to Neapolitan chords (which are harmonic triads and consonant), clusters are not triads (and are, thus, referred to here as nonharmonic); hence, sound expectancy was violated not only in respect of the occurrence of unexpected notes, but additionally in respect to harmony. For the same reasons, clusters are harder to integrate into a harmonic context compared to Neapolitan chords. As in Experiment 1 , stimuli were presented under the instruction to ignore the harmonies and to count the chords played by deviant instruments.

\section{Results}

\section{Clusters at the Fifth Position}

Clusters at the fifth position of the chord sequences elicited, compared to in-key chords, an early-anterior negativity (with an onset around $150 \mathrm{msec}$ ) clearly lateralized to the right (Figures 5a, 11b). Clusters at the fifth position also elicited both a $\mathrm{P} 3 \mathrm{a}$ and a $\mathrm{P} 3 \mathrm{~b}$, the
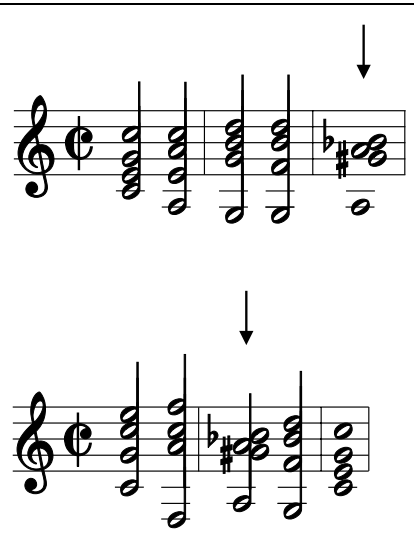

Figure 4. Examples of chord sequences containing tone clusters at the third or fifth position (clusters are indicated by arrows).

latter presumably preceded by an N2b (for an explanation of the functional significance of the $\mathrm{N} 2 \mathrm{~b}$ and $\mathrm{P} 3 \mathrm{~b}$ components, see Discussion). A late frontal-bilateral negativity was evoked with an onset around 500-550 msec. ANOVAs with factors chord type (in-key chords at the fifth position vs. clusters at the fifth position) and lateralization (left frontal vs. right frontal) yielded effects of chord type for both an early (150-210 msec) and a late $(550-610 \mathrm{msec})$ interval $(F(1,16)>32, p$ for both ANOVAs < .0001), as well as an interaction between the two factors for the early (150-210 msec) interval $(F(1,16)=16.03, p<.001)$.

\section{Clusters at the Third Position}

Clusters at the third position of the chord sequences also elicited compared to in-key chords an early-anterior negativity (with an onset around $150 \mathrm{msec}$ ), which was lateralized to the right (especially in respect of frontotemporal electrode sites). Both $\mathrm{P} 3 \mathrm{a}$ and $\mathrm{P} 3 \mathrm{~b}$ are also slightly visible in the ERPs of clusters, followed by a distinct late frontal-bilateral negativity (onset around 500-550 msec, see Figure 5b). Although the right preponderance of the early negativity is clearly visible in the ERPs (cf. FT7 vs. FT8 in Figures 5b, 11b), ANOVAs for the 150-210 msec interval with factors chord type (in-key chords vs. clusters) and lateralization yielded an effect of chord type $(F(1,16)=20, p<.0005)$, but no interaction between the two factors. Analogous ANOVAs conducted for the late time interval (550-610 msec) revealed an effect of condition $(F(1,16)=28.22, p<.0001$, no interaction between the two factors).

\section{Effects of Position}

As in Experiment 1, ERP effects had larger amplitudes when elicited at the fifth position than when elicited at the third position of the cadence. Two-factor ANOVAs, employing chord type (in-key chords vs. clusters) and 


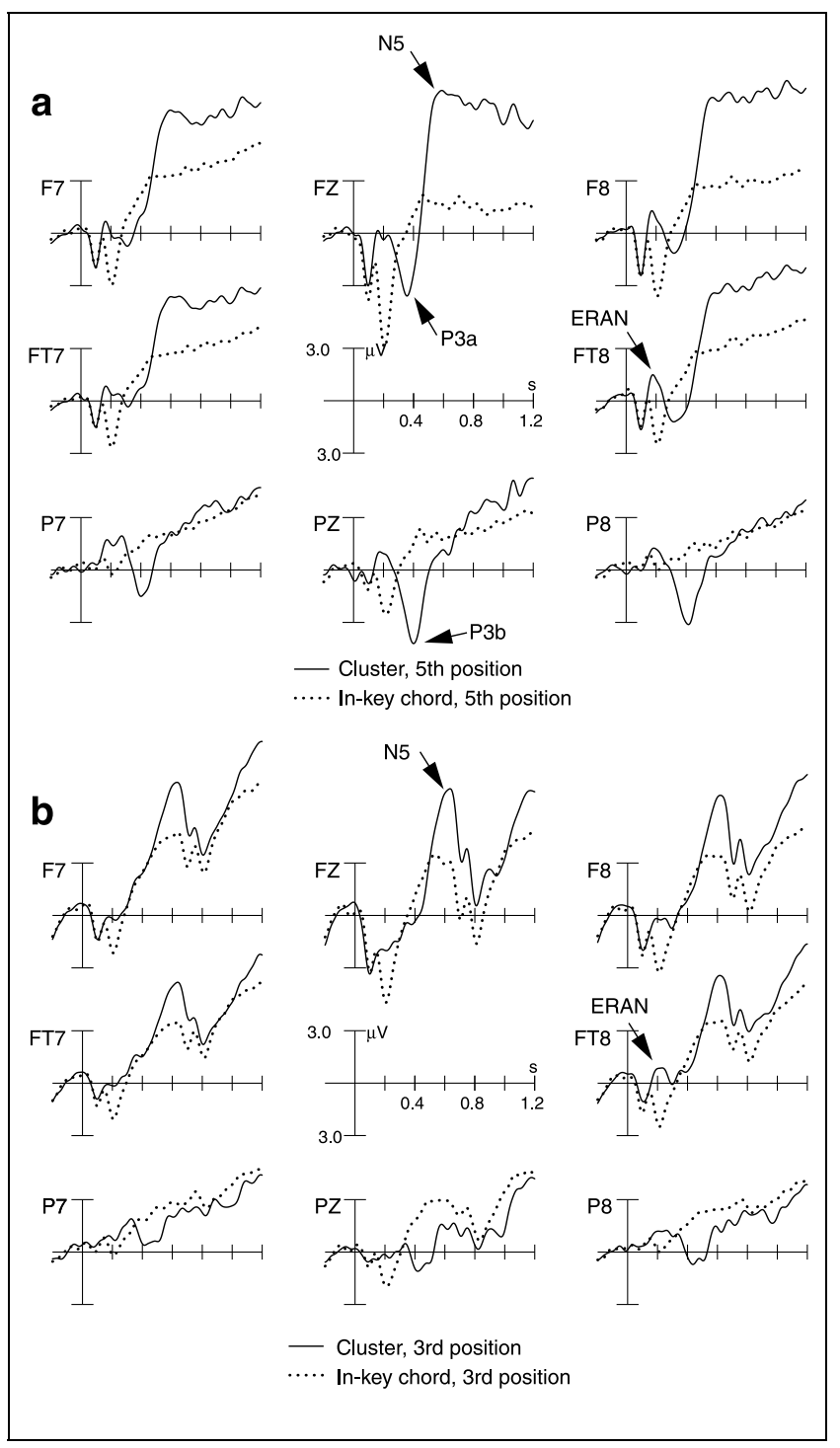

Figure 5. Experiment 2: effects of processing strong musical violations, grand-average ERPs of clusters and in-key chords. (a) Fifth position, (b) third position. Clusters elicited both ERAN and N5. Effects were larger than when elicited by Neapolitans. As when elicited by Neapolitans, effects were smaller for clusters at the third compared to the fifth position.

position of clusters and chords in the cadence (third vs. fifth) as factors revealed an effect of chord type and an interaction between the two factors in both early and late intervals (interaction in the $150-210 \mathrm{msec}$ interval: $F(1,16)=17.77, p<.001$; interaction in the $550-610$ msec interval: $F(1,16)=17.32, p<.001)$.

\section{Degree of Violation-Clusters vs. Neapolitans}

The amplitudes of both the early and the late negativities were larger when elicited by clusters at the third position (Experiment 2) compared to Neapolitan chords at the third position (Experiment 1) of a chord sequence (Figures 3b vs. 5b, 11a vs. b). Whereas Neapolitan chords at the third position in Experiment 1 elicited merely marginally significant effects, distinct early and late negativities were elicited by clusters at the same position. In a between-subjects analysis of variance, comparing data from Experiments 1 and 2, ANOVAs were conducted separately for an early (150-250 msec) and the late (550-610 msec) time interval. Two factors were employed: stimulus type (in-key chords vs. outof-key stimuli [i.e., clusters and Neapolitan chords]) and experiment (stimuli from Experiment 1 vs. stimuli from Experiment 2). An interaction between the two factors was revealed for both time intervals $(150-250$ msec: $F(1,34)=7.85, p<.01 ; 550-610$ msec: $F(1,34)$ $=14.73, p<.0005)$, indicating that both early and late negativities elicited by Neapolitans at the third position differed in amplitude from when elicited by clusters at the same position.

When elicited by clusters at the fifth position, the amplitude of the early negativity was only slightly larger compared to when elicited by Neapolitan chords at the same position. However, this difference was statistically not significant. In contrast, the amplitude of the late negativity was distinctly larger for clusters compared to Neapolitan chords. ANOVAs for stimuli at the fifth position with factors stimulus type (in-key chords vs. out-ofkey stimuli [i.e., clusters and Neapolitan chords]) and experiment (stimuli from Experiment 1 vs. stimuli from Experiment 2) for the 550-610 msec interval yielded an interaction between the two factors $(F(1,34)=13.15, p$ $<.001)$.

\section{Deviant Instruments}

ERPs elicited by the chords that were infrequently played on another instrument compared to chords played on a piano (averaged across all subjects from Experiments 1 and 2) are shown in Figure 6. These chords elicited an early negative component developing from around 150 msec poststimulus on. This component was larger and wider distributed than when elicited by Neapolitan chords or clusters, and tended to be right preponderant. The early negativity was followed by an N2b-P3a-P3b complex (the N2b was centrally maximal and peaked around $220 \mathrm{msec}$, the P3a was frontally maximal and peaked around $380 \mathrm{msec}$, the $\mathrm{P} 3 \mathrm{~b}$ was parietally maximal and peaked around $400 \mathrm{msec}$ ). Following the $\mathrm{P} 3 \mathrm{a}-\mathrm{P} 3 \mathrm{~b}$, a late bilateral-frontal negativity developed peaking around 500-550 msec. When elicited by the deviant instruments, this late-frontal negativity tended to be larger compared to when elicited by Neapolitan chords or clusters. Moreover, the late negativity was larger at right than left electrode sites. ANOVAs with factors instrument (two levels: in-key chords played on a piano vs. chords played on deviant instruments) and lateralization conducted for the $150-210 \mathrm{msec}$ interval revealed an effect of instrument $(F(1,34)=47.67, p<.0001)$, and a marginal interaction between the two factors $(F(1,34)$ 
$=2.95, p<.1$ ). The analogous ANOVAs (factors instrument $\times$ lateralization), done for the 550-610 $\mathrm{msec}$ interval also revealed an effect of instrument $(F(1,34)=$ $39.83, p<.0001)$ and an interaction between the two factors $(F(1,34)=10.59, p<.005)$.

\section{Discussion}

\section{Processing Strong Musical Violations}

Clusters at the third and fifth positions of the cadence elicited an ERAN. Though the lateralization of the ERAN elicited by clusters at the third position was clearly visible in the ERPs (especially at FT7 vs. FT8), it was statistically not significant. However, taking into account the results of all four experiments of the present study, we assume the early negativity elicited by clusters at the third position as an ERAN. Clusters contained out-of-key notes and were not harmonic, the chords preceding clusters were all harmonic, in-key, and built up a harmonic context. Clusters, thus, violated the sound expectancy of listeners, which is (as in the Discussion of Experiment 1) suggested to be reflected in the ERAN. Clusters at both the third and the fifth positions also elicited a late-bilateral negativity (the N5). The N5 was hypothesized to reflect musical integration processes. Though clusters can only hardly be integrated into a harmonic context, the presence of the N5 elicited by clusters is suggested to reflect that nevertheless effort of integration was invested. Notably, this is compatible with results found in N400 experiments, where an N4 was elicited even by nonwords (e.g., Doyle, Rugg, \& Wells, 1996).

\section{Effects of Position}

As in Experiment 1, the amplitudes of both ERAN and N5 were larger when elicited at the fifth than when elicited at the third position of a chord sequence (Figure $5 \mathrm{a}$ vs. b, 11b). It was suggested that the effect of position in the cadence on both ERAN and N5 is due to the preceding musical context (see Discussion of Experiment 1). Moreover, the present data indicate that the large effects elicited by Neapolitan chords at the fifth position in Experiment 1 were not merely due to the fact that the fifth chord was always preceded by a dominant seventh chord (which induced a strong expectancy for the tonic): In Experiment 2, strong musical violations at the third position (which were never preceded by a dominant seventh chord) also resulted in distinct negativities.

Notably, results of the present experiment also indicate that the smaller amplitudes of ERAN and N5 elicited in Experiment 1 by Neapolitans at the third compared to the fifth position were not merely due to the fact that Neapolitans at the third position are culturally more accepted (due to the cultural convention that Neapolitans function as a substitute of the subdominant and,



Figure 6. Experiments 1 and 2: effects of deviant instruments. Grandaverage ERPs from chords infrequently played by deviant instruments compared to chords played on a piano (note the different scaling compared to previous figures). Deviant instruments elicited from around 150-msec poststimulus on an early anterior negativity, and a late negativity that was lateralized to the right.

thereby, as a predominant chord): Clusters also elicited smaller effects at the third compared to the fifth position.

Besides ERAN and N5, clusters elicited also a P3a, an $\mathrm{N} 2 \mathrm{~b}$ and $\mathrm{a} \mathrm{P} 3 \mathrm{~b}$. These components were larger when elicited at the fifth position. Especially in respect of the $\mathrm{P} 3 \mathrm{a}$, this finding supports the interpretation of the ERAN as reflecting sound-expectancy violation: It is plausible to assume that sounds allocate more attention when they are more unexpected (cf. also Näätänen, 1992). The $\mathrm{N} 2 \mathrm{~b}$ is a component that precedes a P3 and is elicited in active oddball paradigms, i.e., when participants detect occasionally presented target stimuli among a series of standard stimuli (cf. Schröger, 1998). The P3b was most presumably due to decisional processes of the listeners (e.g., Näätänen, 1992; Pritchard, 1981): Participants reported that they were tempted to count clusters as deviant instruments, especially when clusters occurred at the fifth position.

\section{Effects of Degree of Violation}

Clusters at the third position elicited both distinct early and late negativities whereas Neapolitan chords at the third position (Experiment 1) showed only marginally significant effects (Figures $3 \mathrm{~b}$ vs. 5b, 11a vs. b). It was hypothesized that the amplitude of the ERAN (and, consequently, of the N5) is a function of the degree of expectancy induced by the preceding musical context. ERPs elicited by clusters confirm this assumption: Clusters violated the sound expectancy in respect to both tonality and harmony. That is, besides out-of-key notes, clusters introduced additionally a frank dissonance. 
Thus, the ERAN evoked by clusters at the third position was larger in amplitude than when elicited by Neapolitans. When elicited at the fifth position of a chord sequence, the amplitude of the ERAN did virtually not differ between clusters and Neapolitans. Given the difference in amplitude observed for the third position, it is proposed that the almost nondifference in the amplitude of the ERAN elicited by a harmonic deviancy at the fifth position is due to the circumstance that it was already maximal in Experiment 1 (and, therefore, did not increase in Experiment 2). However, both clusters at the third and fifth positions also elicited a larger $\mathrm{N} 5$ than the Neapolitan chords at the corresponding positions (suggested to reflect that more effort had to be invested in the integration of clusters compared to the integration of Neapolitans).

Scalp distribution of both ERAN and N5 virtually did not differ when elicited by Neapolitans compared to clusters (Figure 11a vs. b). Thus, the present data do not yield that the neural processes elicited by a dissonant sound differ essentially from effects elicited by harmonically unrelated but consonant sounds (processes differed merely in respect of amplitudes of the electric potentials). Importantly, since both clusters and Neapolitans contained the same amount of unexpected notes, the effects of dissonance (inherent in the data of clusters) could be investigated without confounding with the factor of harmonic expectancy violation (analyzed with data of Neapolitan chords in Experiment 1).

\section{Deviant Instruments}

Deviant instruments elicited a $\mathrm{P} 3 \mathrm{a}-\mathrm{N} 2 \mathrm{~b}-\mathrm{P} 3 \mathrm{~b}$ complex, reflecting the attentional and decisional processes of listeners following the occurrence of a deviant sound. Deviant instruments also elicited compared to piano chords early and late negativities (Figure 6). The lateralization of the early negativity was less distinct than when elicited by clusters or Neapolitans. In contrast, the late negativity was lateralized to the right.

The early negativity is presumably at least partly due to N1 refractoriness and mismatch negativity (since the spectral information of deviant instruments differed from that of the piano; see, e.g., Schröger, 1998). However, due to the huge effect of the early negativity (over $10 \mu \mathrm{V}$ ), an additional effect is regarded here as most probable. Since the sound of a piano was expected and this expectancy was violated by the occurrence of a deviant instrument, it is, thus, suggested that this sound-expectancy violation might also be reflected in the early negativity (similar to when the sound expectancy is violated in the harmonic dimension).

The late negativity is also taken to reflect mainly integration processes: Chords played by deviant instruments were spectrally deviant, but harmonically cor- rect. Thus, these chords fitted in the harmonic context, though the earlier processing (reflected in the early negativity) reported a "violation of sound expectancy." The late negativity is, therefore, also termed N5. The abrupt ending of the N5 elicited by deviant instruments (compared to the N5 elicited by Neapolitan chords) might be due to a "reorienting" towards the harmonic dimension of the cadence (Schröger \& Wolff, 1998).

The lateralization of the N5 elicited by deviant instruments (compared to when elicited by a harmonic deviation) may be due to a different neural mechanism connected to the processing of timbre (as suggested, e.g., by Gaschler-Markefski, Baumgart, Tempelmann, Woldorff, \& Scheich, 1998; Platel et al., 1997). It might also be due to the low probability of the occurrence of deviant instruments (only 10\% of the cadences contained a chord played on a deviant instrument, and each cadence contained 5 chords; thus, only 1 out of 50 chords was played by a deviant instrument). However, the functional significance of the lateralization will not be further determined in this paper.

\section{EXPERIMENT 3: TASK RELEVANCE OF UNEXPECTED CHORDS}

Notably, all formerly discussed ERP effects were elicited under the instruction to ignore the harmonic context and to detect the deviant instruments. This suggests that both ERAN and N5 are elicited even when unexpected musical events are not task-relevant. In order to determine a possible influence of the task relevancy of unexpected chords on ERAN and $\mathrm{N} 5$, the same stimuli as in Experiment 1 were presented under the condition of focusing the participants' attention onto the Neapolitan chords: Participants were informed about the presence of Neapolitan chords and their nature, and instructed to detect the Neapolitan chords. The deviant instruments were to be ignored.

\section{Results}

\section{Behavioral Data}

Participants detected more Neapolitan chords at the fifth position (on average 79\%), than when presented at the third position (58\%). Analyzing the variance of hit percentages at the fifth vs. third position revealed an effect of position $(F(1,17)=57.77, p<.0001)$. Reaction times were on average $559 \mathrm{msec}$ for Neapolitans at the fifth position, and $584 \mathrm{msec}$ for Neapolitan chords at the third position. The false-alarm rate was for both Neapolitans at the third and at the fifth positions just beyond $4 \%$. ANOVAs revealed no difference between reaction times or false alarm rates between the Neapolitans at the fifth and third positions. 


\section{ERP Effects-Chords at the Fifth Position}

Figure $7 \mathrm{a}$ presents the brain responses of detected and undetected Neapolitan chords at the fifth position opposed to in-key chords from the same position. Especially at right-anterior electrode sites, ERPs of Neapolitan chords were from approximately $150 \mathrm{msec}$ on consistently more negative than the ERPs of in-key chords. ERPs of detected compared to ERPs of undetected Neapolitan chords differed particularly at peripheral right anterio-temporal electrode sites (F8, FT8), where the ERP of detected Neapolitans is more negative compared to the ERP of undetected chords. The detected, but not the undetected, Neapolitan chords evoked a P3a (peaking around $380 \mathrm{msec}$ ) and a P3b (peaking around $400 \mathrm{msec}$ ), presumably preceded by an N2b. The P3b was followed by a late bilateral-frontal negative component peaking around 500-550 msec. This late negativity is visible in the ERPs of both detected and undetected Neapolitan chords, but considerably more negative when elicited by undetected Neapolitans.

Since only $21 \%$ of the Neapolitans at the fifth position were undetected, no statistical analyses were carried out for detected and undetected Neapolitans separately. Nevertheless, ANOVAs for the 150-210 msec time interval employing chord type (in-key vs. all Neapolitan chords at the fifth position) and lateralization as factors revealed an effect of chord type $(F(1,16)=54.78, p<$ $.0001)$, and an interaction between the two factors $(F(1,16)=9.92, p<.01)$. Analogous ANOVAs for the 550-610 msec time interval yielded merely a marginal effect of chord type $(F(1,16)=3.9, p<.07)$, and no interaction between the two factors).

\section{ERP Effects-Chords at the Third Position}

Figure $7 \mathrm{~b}$ presents the ERP waveforms of detected and undetected Neapolitan chords at the third position compared to in-key chords at the third position. Detected (but not undetected) Neapolitans at the third position elicited an early negative component that was right-anteriorly predominant, had an onset around 190 msec, and peaked around $230 \mathrm{msec}$ (i.e., the latency of this component was longer than when elicited by Neapolitans at the fifth position). Like Neapolitan chords at the fifth position, and contrary to the ERPs of undetected Neapolitans, a P3a (peaking around $380 \mathrm{msec}$ ) and a P3b (peaking around 400-450 $\mathrm{msec}$ ) is present in the ERPs of detected Neapolitan chords. The P3a-P3b was preceded by a negative deflection, peaking around $290 \mathrm{msec}$, and being right-centrally maximal. This deflection is suggested to be an N2b.

The N2b-P3 complex was followed by a negative deflection that peaked around 500-550 msec. This negative deflection was more negative in the ERPs of undetected Neapolitan chords at the third position compared to the ERPs of in-key chords. In the ERP waveform of detected Neapolitans compared to in-key chords, this deflection is more positive, especially at parietal sites. ANOVAs were conducted for a time interval ranging from 190 to $250 \mathrm{msec}$ (this time window was chosen due to the longer latency of the ERAN for Neapolitans at the third position), employing factors chord type (detected Neapolitans vs. in-key chords) and lateralization (left frontal vs. right frontal). An effect of chord type $(F(1,16)=7.99, p<.05)$, as well as an interaction between the two factors $(F(1,16)=4.88, p<$ .05) was yielded. When levels of chord type were undetected Neapolitans vs. in-key chords, analogous ANOVAs revealed no effect of condition. In contrast, analogous ANOVAs for the 550-610 msec interval revealed an effect when levels of chord type were undetected Neapolitans vs. in-key chords $(F(1,16)=12.8, p<$ .005 , no interaction between the two factors), but not when levels were detected Neapolitans vs. in-key chords. ANOVAs employing the factor detection (detected vs. undetected Neapolitans), carried out for the 190-250 msec interval, revealed an effect of detection $(F(1,34)=$ 8.83, $p<.01)$.

\section{Effects of Position-Third vs. Fifth Position}

As in Experiment 1, the ERAN was larger when elicited by Neapolitans at the fifth position than when elicited by Neapolitans at the third position. ANOVAs with factors position (chords at the third position in the time interval from 190 to $250 \mathrm{msec}$ vs. chords at the fifth position in the time interval from 150 to 210 msec) and chord type (Neapolitans vs. in-key chords) revealed an interaction between the two factors $(F(1,16)=22.19, p<.0005)$. Due to the P3 effects, position effects for the late negativities were not statistically evaluated.

\section{Effects of Task Relevance-First vs. Third Experiment}

Figure 8 shows the difference waveforms from the chords of the fifth position of Experiment 3 (detected and undetected Neapolitan chords subtracted from inkey chords at the same position), opposed to the analogous (but task-irrelevant) stimuli of Experiment 1. The waveforms are highly similar up to $300 \mathrm{msec}$, statistical analyses did not reveal any difference: between-subjects analyses of variances comparing data for the chords at the fifth position from Experiments 1 and 3, conducted for the 150-210 msec interval with factors chord type (inkey vs. Neapolitan chords at the fifth position) and experiment (first vs. third), revealed no interaction between the two factors. A distinct P3b is visible in the ERPs of Experiment 3, but not in those of Experiment 1. The late negativity (from around $500 \mathrm{msec}$ on) is also larger in the waveforms of Experiment 1 compared to Experiment 3. Whereas the late negativity was clearly significant in 
Figure 7. Experiment 3: effects of task relevance. (a) ERPs of detected and undetected Neapolitan chords at the fifth position compared to in-key chords (unrejected trials cumulated over all participants). Especially at right fronto-temporal electrode sites, ERPs of detected Neapolitans are around 150-300 msec distinctly more negative than undetected Neapolitans and in-key chords. Detected, but not undetected, Neapolitans elicited a large P3. Vice versa, undetected, but not detected, Neapolitans elicited a large N5. (b) Grand-average ERPs of detected and undetected Neapolitan chords at the third position compared to in-key chords. Essentially, compared to effects elicited at the fifth position, effects were similar but smaller when elicited at the third position.

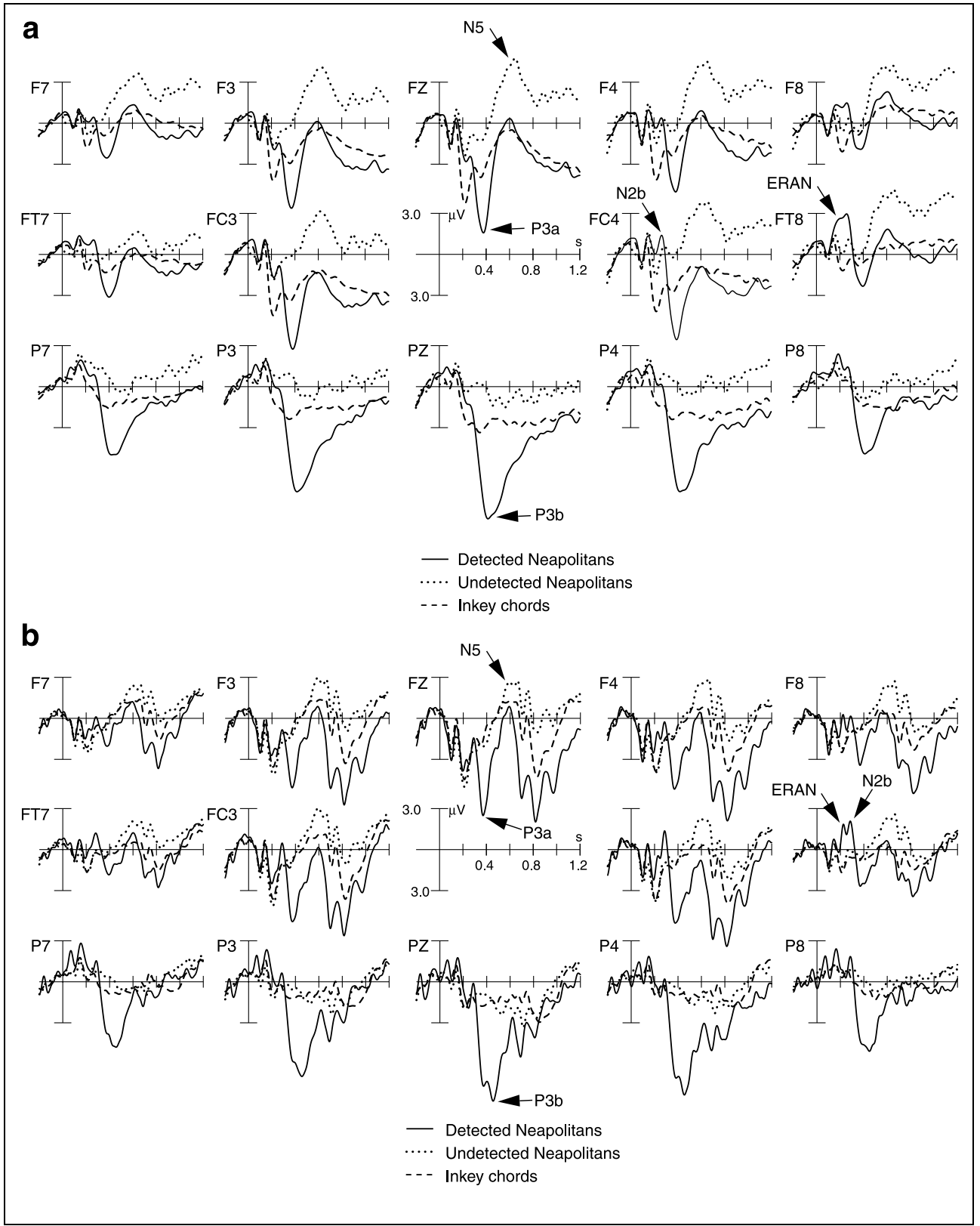

Experiment $1(p<.001)$, it was only marginally significant in the present experiment $(p<.07)$.

Correspondingly, the ERAN elicited by all Neapolitan chords at the third position virtually did not differ between Experiments 1 and 3. For a between-subjects analyses of variances, comparing data from Experiments 1 and 3, ANOVAs were conducted for an interval from 190 to 250 msec employing three factors: chord type (Neapolitans vs. in-key chords at the third position), experiment (first vs. third), and lateralization (left frontal vs. right frontal). Effects were revealed for chord type $(F(1,34)=4.62, p<.05)$, an interaction was yielded between factors chord type $\times$ lateralization $(F(1,34)=$ 8.44, $p<.01)$, and no interaction was yielded between factors chord type $\times$ experiment. The analogous ANOVAs for the 550-610 msec window revealed an effect of chord type $(F(1,34)=4.25, p<.05)$, no interaction between factors chord type $\times$ lateralization, and no interaction between factors chord type $\times$ experiment.

For the same reason as in Experiments 1 and 2, effects of chords that were infrequently played by another instrument compared to chords played on a piano will not be evaluated yet, but together with data of Experiment 4.

\section{Discussion}

\section{Effects of Position}

Participants detected more Neapolitan chords at the fifth compared to the third position. This could only be due to a greater saliency of Neapolitan chords when pre- 
sented at the fifth position of the cadence. Reaction times for both Neapolitans at the fifth and third positions were on average below $600 \mathrm{msec}$; thus, the shorter reaction times could not be due to any physical difference between the chords. The greater saliency of Neapolitan chords at the fifth position is also reflected in the ERPs: As in Experiment 1, the amplitudes of both ERAN and N5 were larger when elicited by Neapolitan chords at the fifth position (Figure $7 \mathrm{a}-\mathrm{b}$ ). As ERPs of Experiment 1 already outlined, the saliency of a Neapolitan also seems to affect the latency of the ERAN, which was prolonged when elicited by Neapolitans at the third position.

It is unlikely that the higher detection rate of Neapolitans at the fifth position (i.e., the greater saliency) was just due to the experimental paradigm, in which only two different chord functions occurred at the fifth position (tonic and Neapolitan), compared to several chord functions at the third position (leading to an easy tonic/nontonic discrimination at the fifth position). The greater saliency is reflected in the larger amplitudes of effects elicited by unexpected sounds occurring at the fifth vs. third position, and is consistent over Experiments 1-3. Importantly, these amplitude differences were even present in Experiment 2, where stimuli at both the third and fifth positions could easily be discerned into harmonic chords vs. nonharmonic clusters. As in the discussions of Experiments 1 and 2, it is rather proposed that the foregoing musical context determined the processing of unexpected chords in respect of amplitudes and latencies of effects.

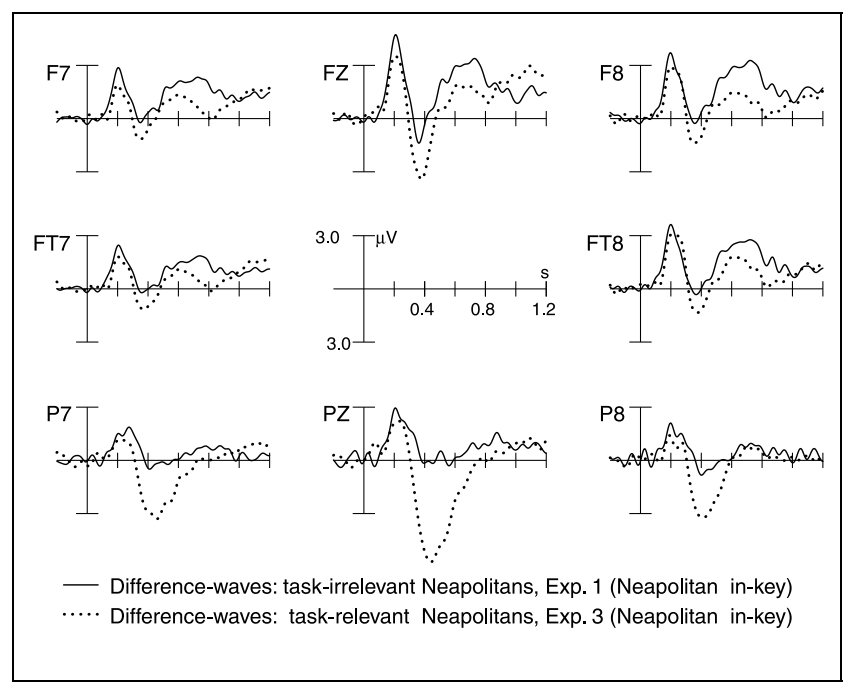

Figure 8. Experiments 1 versus 3: effects of task relevance and detection. Grand-average difference waves: in-key chords at the fifth subtracted from Neapolitan chords at the fifth position from Experiment 1 (solid line), and Experiment 3 (dotted line). Both ERPs virtually do not differ in respect to the ERAN, whereas the N5 elicited in Experiment 1 (Neapolitans were task-irrelevant) was larger than in Experiment 3 (Neapolitans had to be detected).

\section{Effects of Task Relevance}

The statistical analyses did not indicate any difference in amplitude of the ERAN between Experiments 1 and 3 (independently of whether elicited at the third or at the fifth position). Thus, for the time being, this supports the hypothesis that the task relevance of Neapolitan chords has virtually no influence on the ERAN elicited by all Neapolitans. As the ERAN elicited by detected Neapolitans was larger in amplitude compared to undetected Neapolitans, the ERAN seems to reflect processes that determine the conscious saliency (and, thus, detectability) of acoustic events. ERPs also demonstrate that the ERAN is not a frontally distributed N2b: The ERAN was found to be present already around 190 msec; thus, the N2b is presumably the peak in the ERPs of detected Neapolitans around 290 msec (being maximal at right-central electrode sites).

The N5 elicited by all (detected and undetected) Neapolitan chords at the fifth position is still visible in Experiment 3, where Neapolitans were task-relevant. The N5 was only marginally significant in Experiment 3 , but distinctly significant in Experiment 1 (where Neapolitan chords were task-irrelevant; see Figure 8). The reduced N5 in Experiment 3 is most presumably due to positive potentials with an onset around 300 msec ("P3") elicited by detected Neapolitans, which compensated negative potentials in the same latency window (the P3 component is still visible around 600 msec after the onset of detected Neapolitan chords).

\section{Effects of (Non)Detection}

Interestingly, deviant chords were differently processed compared to in-key chords, even when subjects did not consciously realize (i.e., detect) the occurrence of these deviant chords: Undetected Neapolitan chords at the third position of the cadence elicited a distinct $\mathrm{N} 5$, though no ERAN was present (Figure 7b). This suggests that the processes reflected in the ERAN and the N5 (see Discussion of Experiment 1) are independent from each other. An explanation of this independence refers to the Discussion of Experiment 1, where the ERAN was proposed to reflect a violation of musical rules, or "syntax": Neapolitan chords at the third position might not have been perceived as violating a rule (the two out-of-key notes of the Neapolitan chords still fitted well into the harmonic context established by the previous two chords, especially since a Neapolitan might have been perceived as subdominant substitute). Nevertheless, the out-of-key notes of Neapolitan chords were perceived by the listeners (the N5 elicited by Neapolitan chords differs from the N5 elicited by in-key chords). Hence, it is suggested that the out-of-key notes have nonetheless been integrated into the musical context, including an effect on the buildup of the representation of the hierarchy of harmonic stability (both processes pre- 
viously suggested to be reflected by the N5). In other words, out-of-key notes were integrated into the harmonic context though they were not perceived as violating. Therefore, a larger N5 compared to in-key chords occurred without an ERAN. Notably, results suggest that paying attention to the harmonies did not minimize processes reflected in the $\mathrm{N} 5$.

\section{EXPERIMENT 4: EFFECTS OF PROBABILITY}

In Experiments $1-3$ of the present study, the probability of experimental manipulations was 25\%. This contrasts ERP experiments found in the literature (see Introduction), where this probability was $50 \%$. It is interesting to determine an influence of probability on ERAN and N5. In the present experiment, 50\% of the chord sequences contained a Neapolitan chord at the fifth position. No Neapolitan chords occurred at the third position. A reduced amplitude of the ERAN was expected, since within a few trials subjects should be able to anticipate (at least to a certain extent) a Neapolitan chord at the fifth position; thus, the sound of the Neapolitans was less unexpected. The amplitude of the N5 was also expected to be reduced because after a few trials, when the Neapolitans are (at least by some subjects) recognized as sounding like a subdominant, the integration of Neapolitans becomes easier or even unnecessary. As in Experiment 3, participants were instructed to detect the Neapolitan chords and to ignore the deviant instruments.

\section{Results}

\section{Neapolitan chords}

ERP waveforms of the chords at the fifth position are shown in Figure 9a. Neapolitan chords elicited an earlyanterior negativity (onset around $130 \mathrm{msec}$ ), which was only slightly lateralized to the right. Neapolitan chords also elicited a P3a (frontally peaking around $350 \mathrm{msec}$ ), and a P3b (parietally maximal, peak latency around 390 msec). The $\mathrm{P} 3 \mathrm{~b}$ was presumably preceded by an $\mathrm{N} 2 \mathrm{~b}$, which is possibly present in the negative peak around 260 msec. The late-bilateral negative-frontal component, which was elicited by Neapolitan chords in the previous experiments, is merely visible at frontal electrode sites (peaking around $550 \mathrm{msec}$ ).

ANOVAs with factors chord type and lateralization revealed an effect of chord type for the 150-210 msec interval $(p<.005)$, but no interaction between the two factors. ANOVAs for the 550-610 msec interval employing factors chord type $\times$ lateralization revealed no effect of chord type.

\section{Effects of Probability-Experiment 3 vs. 4}

Figure 9b shows the difference waves (Neapolitans minus in-key chords at the fifth position) from Experi-

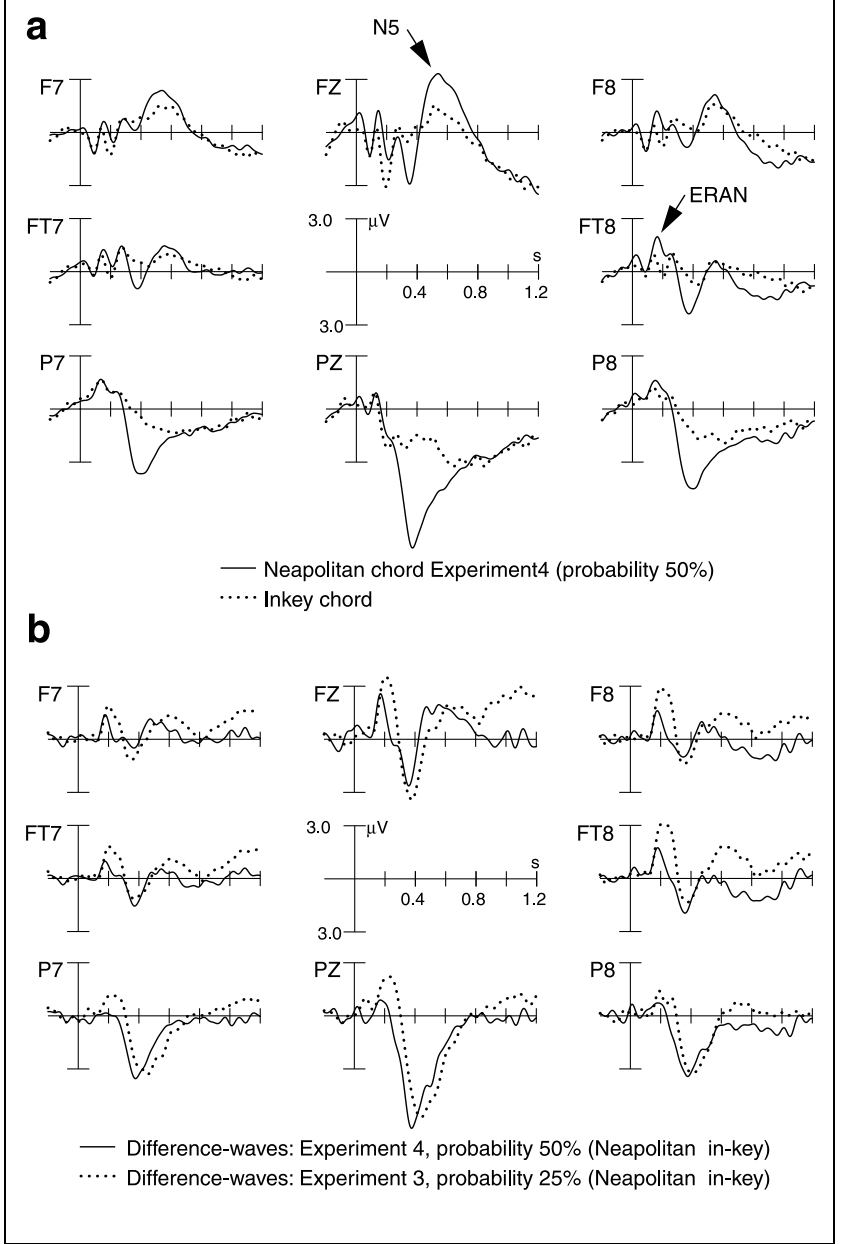

Figure 9. Experiment 4: high probability of violation (50\%). (a) Grand-average ERPs of Neapolitan and in-key chords at the fifth position. (b) Effects of probability. Difference waves (in-key chords subtracted from Neapolitans) from Experiments 4 (solid line) and 3 (dotted line). The ERAN elicited by Neapolitan chords in Experiment 4 was smaller in amplitude compared to Experiment 3 (where Neapolitans occurred with a probability of 25\%). The N5 almost disappeared in Experiment 4.

ments 3 and 4 (see also Figure 11c). Early right-anterior and late-frontal negativities are reduced in the ERP of Experiment 4 (50\% probability for Neapolitan chords), compared to Experiment 3 (25\% probability). Betweensubjects ANOVAs comparing data from Experiments 3 and 4, conducted for the 150-210 msec interval (factors chord type $\times$ experiment), revealed a significant effect of experiment $(F(1,34)=4.25, p<.05)$. Whereas the late negativity elicited by Neapolitan chords was marginally significant in Experiment 3, no late effect was yielded for Neapolitan chords in the present experiment.

\section{Deviant Instruments}

Figure 10 shows the ERPs elicited by the chords that were infrequently played on another instrument compared to chords played on a piano (averaged across all subjects from Experiments 3 and 4). Similarly to Ex- 


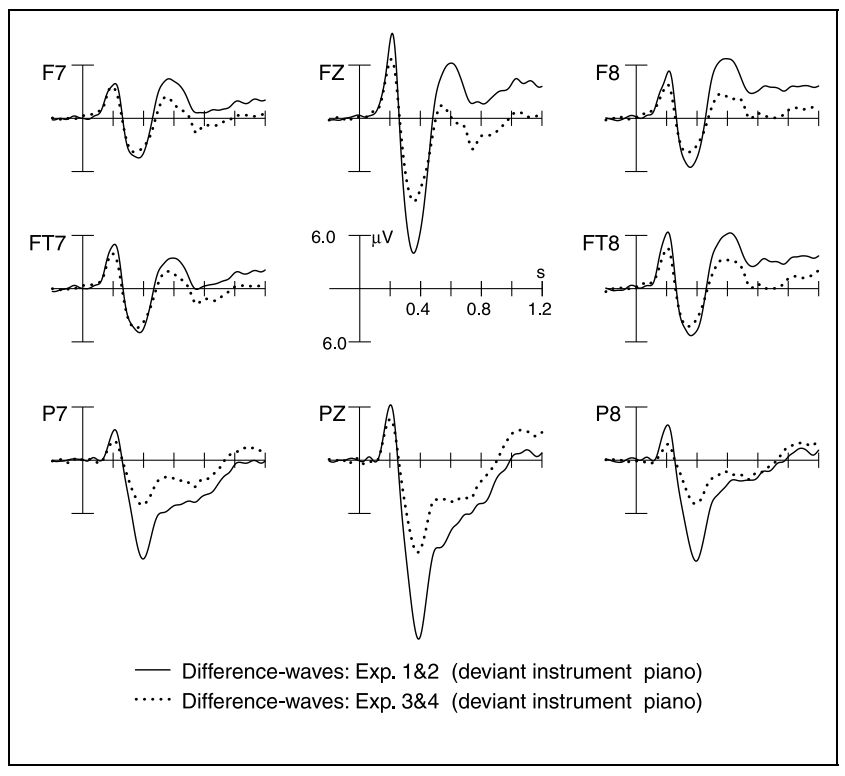

Figure 10. All Experiments: deviant instruments. Grand-average difference-waves: chords played by a piano subtracted from chords played by deviant instruments. Data were averaged across Experiments 1 and 2 (solid line), and Experiments 3 and 4 (dotted line). When to be detected, the P3 elicited by deviant instruments was larger than when elicited under the condition to ignore the deviant instruments. The N5 was larger for attended than for unattended deviant instruments.

periments 1 and 2, these chords elicited an early negative component from around $150 \mathrm{msec}$ poststimulus on which was only slightly right-anteriorly preponderant. Following a P3, a late bilateral-frontal negativity also developed peaking around $500-550$ msec. Both P3 and late negativity were smaller in amplitude than when compared to Experiments 1 and 2. However, as in Experiments 1 and 2, the late-frontal negativity was larger at right than left electrode sites. ANOVAs with factors instrument (two levels: chords played on a piano vs. chords played on deviant instruments) $\times$ lateralization conducted for an early interval (150-250 msec) revealed an effect of instrument $(F(1,34)=$ 90.37, $p<.0001$ ), but no interaction between the two factors. The analogous ANOVAs, done for a late interval (550-650 msec) revealed an effect of instrument $(F(1,34)=5.77, p<.05)$ and an interaction between the two factors $(F(1,34)=14.63, p<.0005)$. Between-subjects ANOVAs with factors instrument $x$ experiments ( 1 and 2 vs. 3 and 4 ) revealed an interaction between the two factors for the late (550-610 msec) interval $(F(1,34)=6.79, p<.05)$. Analogous ANOVAs for the early time interval (150-210 msec) revealed no interaction.

\section{Discussion}

\section{Effects of Probability}

Neapolitan chords elicited an early-anterior negativity, which diminished in amplitude compared to the Nea- politans at the fifth position from the previous experiment (where the probability was $25 \%$; Figures $9 a-b, 11$ ). A lateralization of the early-anterior negativity to the right was consistently observable at fronto-lateral and fronto-temporal electrode sites. Thus, though statistically not significant, we take the early negativity as an ERAN. The results indicate that probability influences the amplitude of the ERAN. An amplitude reduction of the ERAN is plausible, since subjects get familiar with the Neapolitan chords and therefore become able to anticipate them (at least to a certain extent), which made the sound of the Neapolitans less unexpected.

The late bilateral-frontal negativity (N5), which was elicited by Neapolitan chords in the previous experiments, almost disappeared. While in Experiment 3 the N5 elicited by Neapolitans at the fifth position was still marginally significant, it was not significant in the present experiment. This suggests that the probability of a culturally deviant sound influences the amplitude of the N5. This is also plausible, since due to the frequent occurrence of Neapolitans, subjects become soon able to recognize the Neapolitan chords as sounding like a subdominant. This makes the processes of integration easier (if not unnecessary), and prevents from loosening from the hierarchy of the established tonal stability, because Neapolitan chords are now perceived as function within the key, and not as introducing a shift to a new key. Processes of integration, entailing a loosening from the harmonic stability, were hypothesized to be reflected in the $\mathrm{N} 5$.

In respect to Experiments 1 and 3, the present results demonstrate that the larger negativities elicited by Neapolitans at the fifth position (compared to the third position) were not due to a memory-based template (being most specific for the tonic chord at the fifth position, which occurred in $75 \%$ of all cadences): In the present experiment, no tonic-specific template for the fifth chord could be established, since $50 \%$ of the chords at the fifth position were Neapolitans, and 50\% tonic chords. Thus, brain responses of participants actually reflected the principles of distance and relatedness inherent in the major/minor tonal system.

\section{Deviant Instruments}

Similarly to Experiments 1 and 2 (where deviant instruments were to be detected), in Experiments 3 and 4 (where the instrument was to be ignored), chords played by deviant instruments compared to piano chords elicited again early and late negativities (Figure 10). The early negativity had an onset around $150 \mathrm{msec}$, the N5 (peaking around 500-550 msec) was lateralized to the right.

As in the Discussion of Experiment 2, it is proposed that (besides N1 refractoriness and mismatch negativity) a sound-expectancy violation is reflected in the early 


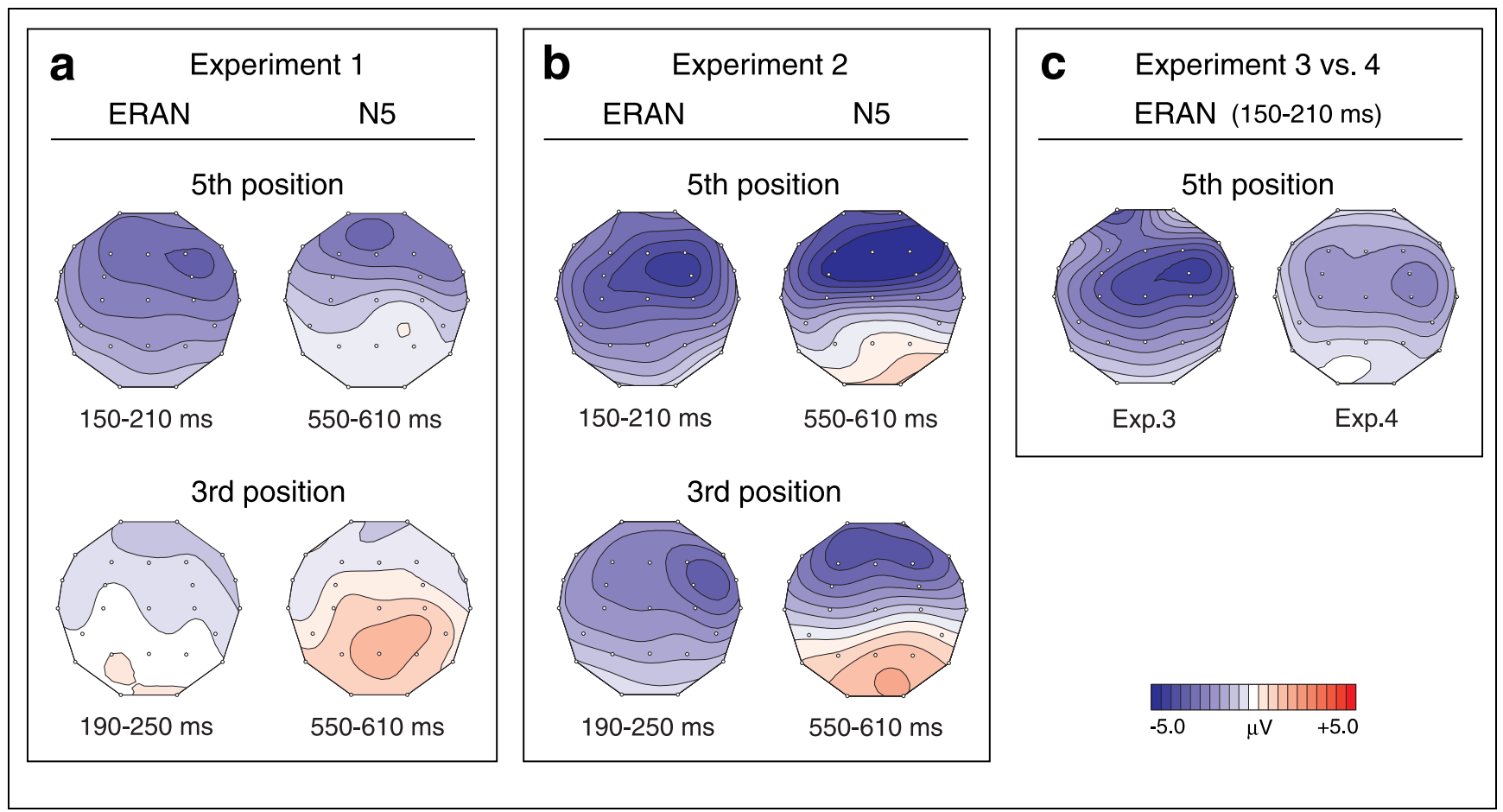

Figure 11. All Experiments: potential-maps of ERAN and N5 elicited by Neapolitan chords (grand-average difference-ERPs, in-key chords subtracted from Neapolitans), seperately for Experiment 1 (a), and 2 (b). Top row: effects elicited by Neapolitans at the fifth position, bottom row: effects elicited at the third position. (c) Analous potential maps of the ERAN elicited by Neapolitans at the fifth position in Experiments 3 (left) and 4 (right).

negativity. The early negativity was followed by a P3, which is hardly to discern into P3a and P3b. The P3 indicates that participants paid attention to the deviant instruments-whether due to the novel sound, or whether they were tempted to respond also to the deviant instruments. The P3 was smaller when elicited in Experiments 3 and 4 compared to Experiments 1 and 2 , presumably due to the fact that participants were instructed to ignore the deviant instruments in Experiments 3 and 4 (and, thus, responded less to them compared to Experiments 1 and 2; e.g., Näätänen, 1992).

The P3 was succeeded by a late negativity, taken as N5, which was lateralized to the right. This lateralization replicates results of experiments 1 and 2. The N5 is again taken to reflect integration processes (see Discussion of Experiment 2), since the chords played by deviant instruments could be integrated as "deviant, but harmonically correct." As the P3, the N5 was also diminished when elicited by deviant instruments in Experiments 3 and 4 compared to Experiments 1 and 2. In Experiments 3 and 4 participants were instructed to detect the Neapolitans, but notably they also paid attention to the deviant instruments (as reflected in the P3). Hence, after paying attention to a deviant instrument in Experiments 3 and 4, participants had to orient their attentional focus back to the task-relevant harmonic dimension of the stimulation. This process might have suppressed further integra- tion of the chords played by a deviant instrument (e.g., recognizing the deviantsound as harmonically correct), resulting in a reduced N5 compared to Experiments 1 and 2.

\section{GENERAL DISCUSSION}

In the present experiments, musical events elicited a number of ERP components. Three of them have previously been described: the P3a, N2b, and P3b. Two ERP deflections appeared which have not yet been reported, to our knowledge, in respect to chord processing: an ERAN (maximal around $150 \mathrm{msec}$ ), and a late bilateralfrontal negativity (maximal around $500-550 \mathrm{msec}$ ). As a working term and for convenience, the former is termed ERAN, the latter N5. The ERAN is taken to reflect the violation of listeners' sound expectancy, the N5 as reflecting musical integration processes. Connected to musical integration is a specification or modification of the tonal schema and the hierarchy of harmonic stability. The N5 decreased in amplitude with progressing inkey chords, reflecting the buildup of musical context. Unexpected musical events elicited both ERAN and N5.

It is important to note that effects elicited by Neapolitan chords (at the fifth position) could only be due to the fact that participants differentiated musically the tonic chords from the Neapolitans. Both tonic and Neapolitan chords occurred in different variations (see 
examples in Figure 1), tonic chords and Neapolitans being on average physically identical. Thus, Neapolitans were not merely physical or frequency "oddballs." Results demonstrate that participants applied their implicit musical knowledge of tonal distance and relatedness while processing the chords.

\section{Effects of Position}

Importantly, the amplitude decline of the N5 elicited by progressing in-key chords depended on the position of the chords in a cadence, rather than on the amount of possible chord functions at each position. For an example: At the third position of the cadences, four chord functions could occur (see Methods section), at the fourth position only one (dominant seventh chord), and at the fifth position two (tonic or Neapolitan). Nevertheless, the N5 elicited by in-key chords was larger at the third compared to the fourth position, and smaller at the fifth compared to the fourth position.

Correspondingly, the amplitudes of both ERAN and N5 elicited by unexpected chords increased when presented at the end of a chord sequence compared to when presented in the middle of a sequence. At the end of a sequence, harmonic expectations of listeners were most specific; thus, Neapolitans at the fifth position were perceived as more unexpected (compared to the third position, where the harmonic expectations were rather unspecified). Consequently, Neapolitan chords at the fifth position needed more integration.

The amplitudes of both ERAN and N5 turned out to be sensitive to the degree of sound-expectancy violation. In the second Experiment, the amplitudes of both ERAN and N5 increased when harmonically unexpected events (half-tone clusters) did not only contain unexpected notes, but were additionally highly dissonant (i.e., nonharmonic). It is important to note that the effects elicited by both clusters (which are nonharmonic, i.e., dissonant) and Neapolitans (which were consonant triads) differed in respect of the amplitudes of ERAN and N5, but not in respect of scalp distribution or time course. Thus, the present data do not indicate that different neural generators are involved in the processing of dissonant events compared to unexpected (but consonant) chords.

Interestingly, the smaller amplitudes of ERAN and N5 elicited by Neapolitans at the third compared to the fifth position could not merely be due to the fact that Neapolitans at the third position are culturally more accepted (due to their function as a subdominant variation), since clusters also elicited smaller effects at the third position.

The early negativity elicited by Neapolitans at the third position in Experiments 1 and 3 was right predominant, though it did not turn out to be statistically significant when analyzed for the two experiments separately.
However, when the data of both experiments were pooled (resulting in a better signal to noise ratio), the lateralization of the ERAN elicited by Neapolitans at the third position was significant.

\section{Effects of Task Relevance}

Data of Experiment 3 indicated that the ERAN is connected to the behavioral discrimination performance. No ERAN was elicited by undetected Neapolitan chords, whereas chords were detected after an ERAN was elicited. Since undetected Neapolitans elicited no ERAN, but an N5, the processes reflected in both ERAN and N5 seem to be independent from each other. The ERAN turned out to be rather insensitive to the relevancy of a task, since it did virtually not differ in amplitude, distribution, or time course between Experiments 1 and 3 .

\section{Effects of Probability}

Experiment 4 (where Neapolitans occurred at the fifth position only) demonstrated that the larger negativities elicited by Neapolitans at the fifth vs. third position in Experiments 1 and 3 were not merely due to a violation of a memory-based template (most specific for the chord at the fifth position being a tonic, which occurred in Experiments 1 and 3 in 75\% of all cadences): In the fourth experiment, no tonic-specific template for the fifth chord could be established, since 50\% of the chords at the fifth position were Neapolitans, and 50\% tonic chords. Nevertheless, Neapolitan chords elicited both an ERAN and a slight N5. This finding demonstrates that listeners (though "nonmusicians") had a musical expectancy that reflected the principles of the major/minor tonal system: Neapolitan chords were only far related to the preceding harmonic context and, thus, perceived as unexpected (which is suggested to be reflected in the ERAN). Besides, Neapolitans required a larger amount of integration into the musical context compared to the musically expected tonic (suggested to be reflected in the larger N5).

Both components were diminished in amplitude in Experiment 4 compared to Experiment 3 (where Neapolitan chords were distributed over the third and fifth positions of the chord sequences). It is suggested that the anticipation of an unexpected musical event reduces the ERAN (if a rule is permanently violated, the violation becomes the new rule), and that the frequent presentation of the Neapolitan led to an ease of integration (reflected in the diminished N5).

\section{Deviant Instruments}

Deviant instruments also elicited (in all experiments) an early negativity (around 150-200 msec) that tended to be right predominant, and a late-frontal negativity 
(around 500-550 msec) that was larger at right than left electrode sites. Several effects might account for the early negativity, e.g., a refractory $\mathrm{N} 1$ and a mismatch negativity (MMN). However, due to the huge potential elicited by deviant instruments, additional processes are presumably involved in the generation of the early negative potential. Since the expectation of a piano sound was violated by the sound of a deviant instrument, processes underlying the ERAN (when elicited by a harmonic deviancy) are thus assumed to be also involved in the processing a deviancy in timbre. The late negativity is suggested to be due to integration processes and, thus, also termed N5: Chords that were spectrally deviant (and, thus, violating the sound expectancy of listeners) were nevertheless harmonically correct and fitted well into the musical context.

Interestingly, participants were tempted to respond to clusters (reflected in the P3b elicited by clusters) though they were instructed to ignore the harmonies. Correspondingly, participants were tempted to respond to deviant instruments when they were instructed to detect the Neapolitans (and to ignore changes of instrument). This indicates that participants responded to a violation of sound expectancy in general, rather than to a violation of harmony or sound in specific.

\section{Comparison to Other ERP Studies}

It is interesting to note that in the study from Patel et al. (1998), a negativity similar to the ERAN has already been described: the RATN. As the ERAN, the RATN was, in term, also taken to reflect a music-specific application of syntactic rules. However, the RATN differs in respect of time-course and distribution from the ERAN. Besides, functional significance and nature of the RATN has not yet been further investigated. Therefore, we prefer, for the time being, the term ERAN for the effects described in the present study.

In a study from Besson and Faïta (1995, e.g., p. 1283) an ERAN might have been present in the ERPs of diatonic incongruent melody endings, though (probably due to the probability of 50\%) not significantly lateralized. Unfortunately, this effect was only speculatively discussed and not further examined. In the study from Hantz et al. (1997) a negative component with a latency of $273 \mathrm{msec}$ was described, but this component was largest at CZ, and due to the decision task presumably an N2b.

To our knowledge, no N5 has explicitly been described in previous ERP studies concerned with the investigation of music processing.

There are some factors that might account for the differences of the effects between previous studies and the present study: The present results yield that both the ERAN and the N5 are affected by the probability, and the N5 by the task relevancy of unexpected chords. Besides, in the present study, the chord sequences were presented one directly after the other, sounding rather like a musical piece than a series of experimental stimuli. This contrasts especially the studies conducted by Hantz et al. (1997) and Janata (1995), where the experimental design was trial-based, each trial consisting of a few chords only. Moreover, in all mentioned studies with harmonic stimulation, participants were musicians, whereas the present study employed "nonmusicians" only. A recent ERP study revealed a difference in preattentive auditory processing of musically relevant information between musicians and nonmusicians (Koelsch, Schröger, \& Tervaniemi, 1999); thus, it is not yet to exclude that ERPs of both groups differ in respect of the stimulation employed in the present study (this issue is under current investigation).

\section{Other Deviance-Related Negativities}

In Experiments 3 and 4, the ERAN elicited by Neapolitan chords was presumably followed, and probably partly overlapped, by an N2b. However, ERPs of Experiment 3 allow to separate the ERAN from the N2b, since both components differ in their time course: Whereas the waveforms of detected Neapolitans suggest the presence of an N2b peaking around $290 \mathrm{msec}$ and being maximal at right-central electrode sites, the ERAN was found to be present already around $190 \mathrm{msec}$ (being right-anteriorly maximal). Hence, ERPs of detected Neapolitans indicate that the ERAN is not just a frontally distributed N2b.

Besides, the ERAN shows some similarities compared with the MMN (for reviews, see Schröger, 1998; Näätänen, 1992). The amplitudes of both the ERAN and the MMN (a) increase with the amount of violation, (b) increase with increasing position in a stimulus train, and (c) are connected to behavioral discrimination performance. Both MMN and ERAN (d) have a right-frontally preponderant distribution, (e) are similar in time course, and (f) are rather insensitive to the relevance of the task. Since the MMN can also be elicited by an abstract feature (e.g., Paavilainen, Jaramillo, \& Näätänen, 1998), the ERAN could be taken as a MMN elicited by the abstract feature "inkey/out-of-key." Hence, it is yet not to exclude that the ERAN is a kind of MMN. However, the comparison of Experiments 3 and 4 suggested that the ERAN is sensitive for effects of anticipation and expectancy. This contrasts the MMN, for which effects similar to those revealed in the present study are not to be expected (cf., e.g., Scherg, Vajsar, \& Picton, 1989 for an experiment with a similar time course; Ritter \& Winkler, 1998). Thus, the processes reflected in the ERAN are, for the time being, suggested as rather specific for the violation of musical expectancies.

Interestingly, the ERAN is also similar to the ELAN (e.g., Friederici, 1995), an ERP component elicited by syntactic incongruities in auditory language experiments. Taking into account the similarities between 
ERAN (and RATN, respectively), ELAN, and MMN, we take these similarities to indicate an amazingly high adaptability of the auditory system.

\section{Conclusion}

In essence, the present study revealed the violation of musical sound expectancy to be reflected in the ERP as an ERAN, and processes of musical integration to be reflected as a late-bilateral negativity (N5). Both ERAN and N5 seem to be independent from each other. No effect of task relevancy was revealed for the ERAN, whereas the N5 was almost compensated by a P3 when Neapolitan chords were detected. Results indicated that both ERAN and N5 are dependent on the probability of the occurrence of unexpected musical events. Determined by the experimental conditions, ERAN and N5 varied in time course, amplitude, and distribution: With increasing expectancy violation, the amplitude of the N5 increased, the ERAN had a greater amplitude with a shorter latency and clearer lateralization. Notably, all participants of the present study were "nonmusicians." Since Neapolitan chords at the third and fifth positions did on average not differ from each other, physically identical acoustic events were differently processed due to the preceding musical context. That is, within a musical context the human brain nonintentionally extrapolates expectations about forthcoming auditory input. These extrapolated expectations are consistent with music theory even in musically untrained listeners. Independently of whether participants got familiar with the major/minor tonal system due to cultural experiences, or whether the tonal system might be inborn in the brain: Participants processed the chords musically and, hence, provided electrophysiological evidence for an implicit musical ability of the human brain.

\section{METHODS}

\section{Experiment 1}

Subjects: 18 subjects (aged 20 to 30 years, mean 22.5, 9 females). Subjects were "nonmusicians," i.e., they had never learned an instrument or singing, and they did not have any special musical education besides normal school education. All subjects were right-handed and reported to have normal hearing.

Stimuli: Stimuli were 172 chord sequences, each consisting of five chords. The first chord was always the tonic of the following cadence. Chords at the second position were tonic, mediant, submediant, subdominant, dominant to the dominant, secondary dominant to mediant, secondary dominant to submediant, secondary dominant to supertonic. Chords at the third position: subdominant, dominant, dominant six-four chord, Neapolitan sixth chord; at the fourth position: dominant seventh chord. Chords a the fifth position: tonic or Neapolitan sixth chord. Neapolitan chords at the third position never followed a secondary dominant. Neapolitan chords at the fifth position never followed a Neapolitan chord at the third position. Secondary dominants, Neapolitan chords at the third position, and Neapolitan chords at the fifth position of the cadence occurred with a probability of $25 \%$ (resulting in a total amount of 43 Neapolitans at the third, and 43 Neapolitans at the fifth position). Effects of secondary dominants will not be discussed in this paper, Neapolitans and in-key chords at the fifth position following a secondary dominant were excluded from data analyses. Chords were presented in different variations (with the third, the fifth or the octave in the top voice). Each variation of a Neapolitan chord was in one cadence presented at the third, and in another at the fifth position. Presentation time of chords 1 to 4 was 600 msec, of the fifth chord $1200 \mathrm{msec}$. All chords had the same decay of loudness, i.e., Neapolitan chords at the third and at the fifth positions were on average physically identical within the first $600 \mathrm{msec}$. Chords were presented via speakers and played under computerized control via MIDI on a synthesizer with approximately $60 \mathrm{~dB}$ SPL. In $10 \%$ of the cadences, an in-key chord at the second, third, fourth or fifth position was played by another instrument than piano (e.g., harpsichord, celesta, marimba). Cadences were played immediately one after the other, sounding like a musical piece.

Procedure: Participants were seated in a comfortable chair. They were instructed to keep their eyes open and to look at a fixation cross. Participants were only informed about the deviant instruments, not about the Neapolitan chords or their nature. An example of a cadence played on a piano and of a cadence in which one chord was played by a deviant instrument (organ) was presented to each participant before starting the EEG measurement. Participants were instructed to ignore the harmonies and to count the deviant instruments. They were informed that they would be asked approximately every $2 \mathrm{~min}$ (i.e., after approximately 35 chord sequences from the same key) about the number of deviant instruments, and report their answer by pressing a response button. This inquiry was employed five times during and at the end of the experiment. After an inquiry, the following chord sequences were from another key (resulting in five "subblocks" from a different key). The duration of the experimental session was approximately $12 \mathrm{~min}$.

\section{Experiment 2}

Subjects: 18 "nonmusicians" (aged 21 to 30 years, mean 23.2, 9 females). None of the subjects participated in Experiment 1.

Stimuli: Stimuli were the same as in Experiment 1, except that Neapolitan chords were replaced by half- 
tone clusters. These clusters consisted (in respect to the tonic) either of minor sixth, major sixth, and minor seventh, or of minor second, major second, and minor third. Thus, clusters contained the same amount of unexpected notes as Neapolitan chords, and were physically on average almost identical to Neapolitan chords.

Procedure: Procedure was the same as in Experiment 1.

\section{Experiment 3}

Subjects: 18 "nonmusicians" (aged 21 to 29 years, mean 23, 9 females). None of the subjects participated in either of the previous two experiments.

Stimuli: Stimuli were the same as in Experiment 1.

Procedure: Procedure was identical to Experiment 1, except that participants were informed about Neapolitan chords and their nature, and instructed to respond to the Neapolitan chords by immediately pressing a response button. As examples, two cadences exclusively consisting of in-key chords were presented, as well as two cadences containing a Neapolitan chord at the third, and two cadences with a Neapolitan chord at the fifth position. Subjects were also informed about the infrequent occurrence of deviant instruments and instructed to ignore these deviant instruments.

\section{Experiment 4}

Subjects: 18 "nonmusicians" (aged 20 to 29 years, mean 23.7, 9 females). None of the subjects participated in one of the previous experiments.

Stimuli: Stimuli were the same as in Experiments 1 and 3, except that Neapolitan chords occurred at the fifth position only with a probability of 50\%, and except that secondary dominants also occurred with a probability of $50 \%$.

Procedure: Procedure was the same as in Experiment 3, except that the examples were two cadences of in-key chords, and two with a Neapolitan sixth chord at the fifth position of the cadence (since no Neapolitan was presented at the third position).

\section{EEG Measurements}

Measurements were performed in an acoustically and electrically shielded room. The EEG was recorded with $\mathrm{Ag}-\mathrm{AgCl}$ electrodes from 25 scalp locations of the 10-20 system (vertical and horizontal electro-oculogram exclusive), referenced to the left mastoid (cf. Pivik et al., 1993). Sampling rate was $250 \mathrm{~Hz}$ (bandpass .5-40 Hz). For elimination of artifacts caused by eye movements, EEG data were rejected off line from the raw EEG whenever the standard deviation within any $200 \mathrm{msec}$ interval of all data exceeded $35 \mu \mathrm{V}$ in the vertical, and 15 $\mu \mathrm{V}$ in the horizontal electro-oculogram. For elimination of artifacts caused by drifts or movements, EEG data were rejected off line from the raw EEG whenever the standard deviation within any $500 \mathrm{msec}$ interval of all data exceeded $20 \mu \mathrm{V}$ at either of the following electrodes: T7, T8, FT7, FT8, P7, P8, O1, and O2. On average, 9.5\% of all trials were rejected from further data analysis. The baseline for the ERP waveforms was defined as the mean amplitude between $-200 \mathrm{msec}$ and the onset of a chord.

\section{Data Analysis}

To test the lateralization of effects, repeated measurement ANOVAs were conducted comparing left-frontal vs. right-frontal electrodes. Therefore, two regions of interest were computed: a region of left-frontal electrodes (F7, F3, FT7, FC3) and a region of right-frontal electrodes (F4, F8, FC4, FT8). If not separately indicated in the paper, variances of ERPs were analyzed by repeated measures as univariate tests of hypotheses for withinsubjects effects. The same procedure was applied to analyze variances of hit rates, false-alarm rates, and reaction times obtained in Experiment 3. After the statistical evaluation, ERPs of Figures 2, 3, 5, 8 and 9 were for presentation 10 Hertz low pass filtered ( 51 points, FIR).

\section{Acknowledgments}

Examples of the stimuli are available at http://www.cns.mpg.de/ Staff/homepages/koelsch@cns.mpg.de.html.

Reprints requests should be sent to: Stefan Koelsch, MaxPlanck-Institute of Cognitive Neuroscience, Stephanstrasse 1a, D-04103 Leipzig, Germany (e-mail: koelsch@cns.mpg.de).

\section{Note}

1. To describe the sound of a Neapolitan chord subjectively: When presented in a major-tonal context instead of a subdominant, a Neapolitan sounds "uncommon, but not false." When presented instead of a tonic chord, a Neapolitan sounds "false."

\section{REFERENCES}

Berent, I., \& Perfetti, C. A. (1993). An on-line method in studying music parsing. Cognition, 46, 203-222.

Besson, M., \& Faïta, F. (1995). An event-related potential (ERP) study of musical expectancy: Comparison of musicians with nonmusicians. Journal of Experimental Psychology: Human Perception and Performance, 21, 12781296.

Besson, M., \& Friederici, A. D. (1998). Language and music: A comparative view. Music Perception, 16, 1-9.

Bharucha, J. (1984). Anchoring effects in music: The resolution of dissonance. Cognitive Psychology, 16, 485-518.

Bharucha, J., \& Krumhansl, C. (1983). The representation of harmonic structure in music: Hierarchies of stability as a function of context. Cognition, 13, 63-102.

Bharucha, J., \& Stoeckig, K. (1986). Reaction time and musical expectancy: Priming of chords. Journal of Experimental Psychology: Human Perception and Performance, 12, 403410 
Bharucha, J., \& Stoeckig, K. (1987). Priming of chords: Spreading activation or overlapping frequency spectra? Perception and Psychophysics, 41, 519-524.

Bigand, E., Madurell, F., Tillmann, B., \& Pineau, M. (1999). Effect of global structure and temporal organization on chord processing. Journal of Experimental Psychology: Human Perception and Performance, 25, 184-197.

Bigand, E., \& Pineau, M. (1997). Global context effects on musical expectancy. Perception and Psychophysics, 59, 1098-1107.

Brown, C. M., \& Hagoort, P (1993). The processing nature of the N400: Evidence from masked priming. Journal of Cognitive Neuroscience, 5, 34-44.

Doyle, M. C., Rugg, M. D., \& Wells, T. A. (1996). A comparison of the electrophysiological effect of formal and repetition priming. Psychophysiology, 33, 132-147.

Friederici, A. D. (1995). The time course of syntactic activation during language processing: A model based on neuropsychological and neurophysiological data. Brain and Language, 50, 259-281.

Friederici, A. D., Pfeifer, E., \& Hahne, A. (1993). Event-related brain potentials during natural speech processing: Effects of semantic, morphological and syntactic violations. Cognitive Brain Research, 1, 183-192.

Gaschler-Markefski, B., Baumgart, F., Tempelmann, C., Woldorff, M. G., \& Scheich, H. (1998). Activation of human auditory cortex in retrieval experiments: An fMRI study. Neural Plasticity, 6, 69-75

Gunter, T. C., \& Friederici, A. D. (1999). Concerning the automaticity of syntactic processing. Psychophysiology, 36, 126-137.

Hagoort, P., Brown, C., \& Groothusen, J. (1993). The syntactic positive shift (SPS) as an ERP measure of syntactic processing. Language and Cognitive Processes, 8, 439-483.

Hantz, E. C., Kreilick, K. G., Kananen, W., \& Swartz, K. P. (1997). Neural responses to melodic and harmonic closure: An event-related-potential study. Music Perception, 15, 69-98.

Holcomb, P. J., \& Neville, H. J. (1991). Natural speech processing: An analysis using event-related brain potentials. Psychobiology, 19, 286-300.

Janata, P. (1995). ERP measures assay the degree of expectancy violation of harmonic contexts in music. Journal of Cognitive Neuroscience, 7, 153-164.

Jones, M. R. (1981). Music as stimulus for psychological motion: Part I. Some determinants of expectancies. Psychomusicology, 1, 34-51.

Jones, M. R. (1981). Music as stimulus for psychological motion: Part II. An expectancy model. Psychomusicology, 2, 1-13.

Koelsch, S., Schröger, E., \& Tervaniemi, M. (1999). Superior pre-attentive auditory processing in musicians. NeuroReport, 10, 1309-1313.

Krumhansl, C. L. (1979). The psychological representation of musical pitch in a tonal context. Cognitive Psychology, 11, 346-374

Krumhansl, C. L., Bharucha, J., \& Castellano, M. A. (1982). Key distance effects on perceived harmonic structure in music. Perception and Psychophysics, 32, 96-108.

Krumhansl, C. L., Bharucha, J., \& Kessler, E. J. (1982). Perceived harmonic structure of chords in three related musical keys. Journal of Experimental Psychology: Human Perception and Performance, 8, 24-36.

Krumhansl, C. L., \& Kessler, E. J. (1982). Tracing the dynamic changes in perceived tonal organization in a spatial representation of musical keys. Psychological Review, 89, 334-368.

Krumhansl, C. L., \& Shepard, R. N. (1979). Quantification of the hierarchy of tonal functions within a diatonic context. $E x$ perimental Psychology: Human Perception and Performance, 5, 579-594.

Kutas, M., \& Dale, A. M. (1997). Electrical and magnetic readings of mental functions. In M. D. Rugg (Ed.), Cognitive neuroscience (pp. 197-242). Cambridge: MIT Press.

Meyer, L. (1956). Emotion and meaning in music. Chicago: University of Chicago Press.

Näätänen, R. (1992). Attention and Brain Function. Hillsdale, NJ: Erlbaum.

Osterhout, L., \& Holcomb, P. J. (1993). Event-related potential and syntactic anomaly: Evidence of anomaly detection during the perception of continuous speech. Language and Cognitive Processes, 8, 413-437.

Paavilainen, P., Jaramillo, M., \& Näätänen, R. (1998). Binaural information can converge in abstract memory traces. Psychophysiology, 35, 483-487.

Patel, A. D., Gibson, E., Ratner, J., Besson, M., \& Holcomb, P. J. (1998). Processing syntactic relations in language and music: An event-related potential study. Journal of Cognitive Neuroscience, 10, 717-733.

Pivik, R. T., Broughton, R. J., Coppola, R., Davidson, R. J., Fox, N., \& Nuwer, M. R. (1993). Guidelines for the recording and quantitative analysis of electroencephalographic activity in research contexts. Psychophysiology, 30, 547-558.

Platel, H., Price, C., Baron, J. C., Wise, R., Lambert, J., Frackowiak, R. S. V., Lechevalier, B., \& Eustache, F. (1997). The structural components of music perception, a functional anatomical study. Brain, 120, 229-243.

Pritchard, W. S. (1981). Psychophysiology of P300: A review. Psychological Bulletin, 89, 506-540.

Ritter, W., \& Ruchkin, D. S. (1992). A review of eventrelated potential components discovered in the context of studying P3. Annals of the New York Academy of Sciences, 658, 1-32.

Ritter, W., \& Winkler, I. (1998). An examination of the basic issues associated with the MMN: Memory, processes, and functions. In M. Tervaniemi \& C. Escera (Eds.), Abstracts of the first international workshop on mismatch negativity and its clinical applications (p. 6). Helsinki, Finland: Multiprint University of Helsinki.

Scherg, M., Vajsar, J., \& Picton, T. W. (1989). A source analysis of the late human auditory evoked potentials. Journal of Cognitive Neuroscience, 1, 336-355.

Schönberg, A. (1957). Die formbildenden Tendenzen der Harmonie. Mainz, Germany: Schott.

Schröger, E. (1998). Measurement and interpretation of the mismatch negativity (MMN). Behavior Research Methods, Instruments, and Computers, 30, 131-145.

Schröger, E., \& Wolff, Chr. (1998). Attentional orienting and reorienting is indicated by human event-related brain potentials. NeuroReport, 9, 3355-3358.

Tervaniemi, M., Winkler, I., \& Näätänen, R. (1997). Pre-attentive categorization of sounds by timbre as revealed by eventrelated potentials. NeuroReport, 8, 2571-2574.

Van Petten, C., \& Kutas, M. (1990). Interactions between sentence context and word frequency in event-related brain potentials. Memory and Cognition, 18, 380-393. 